\title{
Relatos para una revolución potencial. Las crónicas testimoniales de Che Guevara
}

\author{
Narratives for a Potential Revolution. Testimonial Chronicles by Che Guevara
}

\author{
JaUMe PERIS Blanes \\ UNIVERSITAT DE VALÈNCIA · jaume.peris@uv.es
}

Profesor de literatura y cultura latinoamericana, ha publicado numerosos artículos sobre testimonio, cultura y política en América Latina, así como los libros La imposible voz. Memoria y representación de los campos de concentración en Chile: la posición del testigo. (2005) e Historia del testimonio chileno. De las estrategias de denuncia a las políticas de la memoria (2008). Actualmente investiga las relaciones entre cultura y política en los años sesenta y setenta en América Latina y la producción cultural ligada a movimientos sociales en la España actual.

Resumen: Este artículo analiza los textos narrativos de Ernesto Guevara, habitualmente englobados bajo la rúbrica de 'testimonio'. Más que el anacronismo de ajustar la propuesta guevariana a las formulaciones y conceptualizaciones del testimonio que vendrían después, interesa definir con detalle la apuesta de Guevara en su historicidad, para tratar de restituir a sus textos la potencialidad revolucionaria desde la que fueron escritos y que constituyó una de las respuestas posibles a los debates sobre la naturaleza y la función de la cultura en tiempos de revolución. En ese sentido, el artículo pone el acento en el lugar que la escritura narrativa tuvo en el interior del proyecto político de Guevara, como espacio para generar prácticas de emulación revolucionaria. Es por ello que las crónicas de Guevara pueden leerse como un material narrativo pensado para nutrir la revolución mundial potencial.

Palabras clave: Guevara, Revolución Cubana, Testimonio, Emulación, Hombre Nuevo.
Abstract: This paper deals with the narrative texts of Che Guevara, usually called 'testimonio'. More than adjusting its texts to the theories of 'testimonio', we try to describe the historicity of Guevara's narrative, trying to keep its revolutionary potentiality. The article, then, focus in the place Guevara gave to its narrative writing within its political project, as a place for generating emulation processes. That is the reason why its testimonial chronicles can be read as a narrative food for the world potential revolution.

Key words: Guevara, Cuban Revolution, Testimony, Emulation, New Man. 
Jaume Peris Blanes. Relatos para una revolución potencial...

\section{Un corpus heterogéneo y problemático}

Es ya un lugar común situar algunos textos del Che Guevara, y especialmente sus Pasajes de la guerra revolucionaria, como un antecedente del estallido de la escritura testimonial que tuvo lugar en América Latina en la segunda mitad de los años sesenta y que iba a consolidarse durante los años setenta y ochenta. Efectivamente, algunas de las intervenciones de Guevara desempeñaron un rol fundamental en el desarrollo de la cultura latinoamericana de la época y, en el clima de radical politización de la cultura de los años sesenta y setenta, la figura de Guevara llegó a erigirse en una suerte de modelo cultural y, sobre todo, en un fetiche cultural de largo alcance, que iba a modificar, en buena medida, la concepción general de la figura del intelectual y del trabajo cultural en un contexto revolucionario ${ }^{1}$.

Fue en ese contexto de crítica y cuestionamiento del intelectual, que la figura magnética y el discurso teórico de Guevara alentaron, en el que las escrituras testimoniales encontraron su caldo de cultivo y su hábitat privilegiado de desarrollo. En ese sentido, la obra de Guevara y los sentidos sociales que se derivaron de su biografía fueron, sin duda, elementos claves para la emergencia y consolidación del testimonio como discurso culturalmente legitimado. Sin embargo, los textos narrativos publicados en vida por Guevara y aquellos que se publicarían tras su muerte son, a pesar de sus fuertes tensiones internas, solidarios de una concepción de la escritura muy diferente a las que pueden hallarse en las conceptualizaciones posteriores del testimonio y que, por el contrario, se halla totalmente integrada en el pensamiento político de Guevara y en su concepción de la lucha, la subjetividad y la cultura.

El objetivo principal de estas páginas consiste en analizar la especificidad de la escritura narrativa de Guevara y reflexionar sobre el sentido que esa escritura tenía en el interior de su proyecto político y cultural. Acercarse a los textos narrativos de Guevara supone acercarse a un momento en el que no habían surgido todavía las categorías que iban a abrochar una gran heterogeneidad discursiva bajo el rótulo de lo testimonial. Por ello, más que el anacronismo de ajustar la propuesta guevariana a las formulaciones y conceptualizaciones del testimonio que vendrían después, interesa definir con detalle la apuesta de Guevara en su historicidad, para tratar de restituir a sus textos la potencialidad revolucionaria desde la que fueron escritos y que constituyó una de las respuestas posibles a los debates sobre la naturaleza y la función de la cultura en tiempos de revolución.

Para ello, nos acercaremos a los textos narrativos escritos por Guevara a lo largo de los años sesenta y a otras publicaciones aledañas, que guardan una estrecha relación con esa producción narrativa. Y lo haremos poniendo el acento en el lugar que su escritura adquiere en el proyecto político,

\footnotetext{
${ }^{1}$ En el otoño de 2003 pude asistir al seminario "Ernesto Che Guevara entre historia y literatura", impartido por Ricardo Piglia en Princeton University, en el que surgieron algunas de las preguntas que originaron este trabajo. Vaya por delante, pues, mi agradecimiento y mi deuda intelectual con Piglia y con los participantes en aquel seminario seminal.
} 
Jaume Peris Blanes. Relatos para una revolución potencial...

siempre en construcción y reelaboración, que a lo largo de una década iría construyendo Guevara. Se tratará aquí, pues, de un corpus heterogéneo y que hace referencia a procesos y vivencias históricas y personales de una naturaleza muy diversa. ¿Cuáles son, pues, esos textos y a qué experiencias aluden?

Antes de convertirse en guerrillero, Guevara llevó a cabo dos grandes viajes por América Latina: de ambos se conservan textos que anuncian ya una primera dedicación a la escritura documental. El primero de esos viajes, que realizó en 1952 en compañía de Alberto Granado desde Argentina a Venezuela en una vieja motocicleta ${ }^{2}$ dio lugar a las Notas de viaje $^{3}$, un texto que no sería publicado hasta 1992, pero que Guevara elaboró a partir de las notas originales tomadas durante el viaje y cuyo proceso de escritura sirvió, sin duda, como laboratorio de experimentación para sus crónicas posteriores. Del segundo viaje, iniciado junto a Carlos Ferrer en 1953, se publicaron en 2000 algunos de sus diarios y apuntes, con el título de Otra vez. Diario inédito del segundo viaje por Latinoamérica.

Pero sin duda el núcleo central de su producción narrativa es el que refiere a su experiencia en la lucha insurreccional cubana. Pasajes de la guerra revolucionaria [1963] recogía las crónicas escritas sobre ella, algunas de las cuales habían sido publicadas previamente en la revista del ejército Verde Olivo. Las mismas experiencias habían servido de material de base para un texto anterior, La guerra de guerrillas [1960], que aunque no era, en rigor, un texto narrativo, sino un ensayo o un manual pedagógico, compartía algunos elementos fundamentales con Pasajes de la guerra revolucionaria. En cierto modo, como se verá, eran textos complementarios, que se inscribían en una pedagogía revolucionaria que hacía de la experiencia cubana un modelo ejemplar digno de ser emulado internacionalmente y que se nutrían de las anotaciones que Guevara había tomado en sus diarios de campaña, que recientemente han sido publicados bajo el título de Diario de un combatiente (2011). Tal como narraba Fidel Castro,

era costumbre del Che en su vida guerrillera anotar cuidadosamente en un diario personal sus observaciones de cada día. En las largas marchas por terrenos abruptos y difíciles, en medio de los bosques húmedos, cuando las filas de los hombres, siempre encorvados por el peso de las mochilas, las municiones y las armas, se detenían un instante a descansar, o la columna recibía la orden de alto para acampar al final de fatigosa jornada, se veía al Che, como cariñosamente lo bautizaron desde el principio los cubanos, extraer una pequeña libreta y con su letra menuda y casi ilegible de médico escribir sus notas (Castro en Guevara [1970]: 437).

El mismo patrón de escritura se repetiría en relación con las otras dos grandes experiencias guerrilleras en las que Guevara iba a participar en los años siguientes, y que desembocarían en dos

\footnotetext{
${ }^{2}$ A pesar de que varias ediciones del texto y la adaptación cinematográfica de Walter Salles hayan puesto el acento en la motocicleta, lo cierto es que buena parte del trayecto hubo de hacerse en otros medios de transporte.

${ }^{3}$ El texto fue editado en los años siguientes con el título Mi primer gran viaje: de la Argentina a Venezuela en motocicleta.
} 
Jaume Peris Blanes. Relatos para una revolución potencial...

sonoros fracasos. De la experiencia del Congo en 1965, rodeada de secretismo y opacidad, Guevara escribiría un texto que debía leerse en continuidad -aunque, como veremos, con sentido opuesto- a sus crónicas de la guerrilla cubana: Pasajes de la guerra revolucionaria: el Congo no iba a publicarse hasta más de treinta años después de su muerte, en 1999, tras permanecer varias décadas oculto. De la experiencia boliviana en 1967, que le llevó a la muerte, no pudo llegar a elaborar ningún texto unitario ni narrativamente articulado. Pero quizás por ello mismo su Diario de Bolivia, con sus discontinuidades, fisuras y lagunas, tenga todavía la capacidad de evocar una experiencia histórica truncada, llena de contradicciones y atravesada por múltiples violencias y desgarros.

¿Cómo pensar, pues, estos textos de diferente naturaleza, escritos en un periodo relativamente corto pero radicalmente acelerado e intenso? ¿De qué modo se relacionaban estos textos narrativos con los ensayos de Guevara, con su proyecto político y con su peculiar forma de concebir la relación entre la ciudadanía y la revolución? ¿En qué sentido pueden relacionarse con la categoría de 'testimonio' que iba a consolidarse en los años posteriores y en qué sentido la propuesta de Guevara trabajaba en una dirección opuesta a ella? ¿Cuál era, pues, la función que Guevara daba implícitamente a estas escrituras a las que dedicó una energía y dedicación que parecería contradecir la dicotomía entre hombre de letras y hombre de acción que sobrevolaba en los discursos revolucionarios de la época ${ }^{4}$ ?

\section{Hacia una nueva escritura documental}

En las Notas de viaje en las que dio cuenta de su primer viaje por América Latina, Guevara ofrecía algunas pistas del modo en que sus textos posteriores iban a afrontar la relación entre escritura y experiencia vivida. En realidad, no se trataba de las notas originales tomadas durante el viaje, sino de un texto posterior, redactado a partir de ellas, en las que Guevara ordenaba, pulía y dotaba de narratividad a las anotaciones viajeras. En una introducción sorprendente, afirmaba:

¿Que nuestra vista nunca fue panorámica, siempre fugaz y no siempre equitativamente informada, y los juicios son demasiado terminantes?: de acuerdo, pero ésta es la interpretación que un teclado da al conjunto de los impulsos que llevaron a apretar las teclas y esos fugaces impulsos han muerto. No hay sujeto sobre quien ejercer el peso de la ley. El personaje que escribió estas notas murió al pisar de nuevo tierra Argentina, el que las ordena y pule, 'yo, no soy yo'; por lo menos no soy el mismo yo interior. Ese vagar sin rumbo por nuestra 'Mayúscula América’ me ha cambiado más de lo que creí (Guevara, 1992: 17-18).

\footnotetext{
${ }^{4}$ En un artículo sagaz, Paola Cortés analiza la abundancia de fotografías del Che en las que aparece leyendo: "El joven, el rebelde, el hombre de acción con un libro en la mano interrogan y transforman el modo en que pensamos la lectura, asociada a la improductividad, la inacción, la soledad y el ejercicio burgués. En las fotografías del Che lector, se desafía también ese supuesto antagonismo entre imágenes y palabras que es parte de otros de los lugares comunes de la imaginación cultural" (2014: 12).
} 
Jaume Peris Blanes. Relatos para una revolución potencial...

De ese breve fragmento pueden extraerse, al menos, tres consideraciones de calibre. En primer lugar, la limitación del punto de vista del que da cuenta una escritura ligada a la experiencia personal, incapacitada para una 'visión panorámica', detenida y 'equitativamente informada'; es decir, la constatación de que ese tipo de escritura era incapaz de articular una visión global del acontecimiento que trataba de describir. En segundo lugar, la explicitación de dos tiempos diferenciados de escritura: uno contemporáneo a las acciones narradas, y otro muy posterior, ya desde la distancia temporal, en el que se retomaban, reelaboraban y reordenaban las notas escritas en la vorágine de los acontecimientos, otorgándoles un sentido global y una continuidad estilística que no tenían necesariamente en su origen. En tercer lugar, y relacionado con el anterior, el énfasis en la transformación del sujeto que, a la vez, protagonizaba y narraba los acontecimientos: una transformación, pues, que afectaba a la naturaleza de los hechos narrados, pero también al lugar de enunciación desde el que eran contados.

Esos tres elementos iban a jugar un rol esencial en la función que Guevara otorgó a la escritura narrativa en el interior de su proyecto político e iban a determinar, en buena medida, el sentido de su proyecto testimonial. Este se sostenía sobre una aparente contradicción: la voluntad documental, de dejar constancia de lo vivido, visto y ocurrido, contrastaba con su anclaje a un sujeto con un punto de vista precario, que actuaba de filtro sensorial e ideológico y que además no era un sujeto estable y uniforme, sino que se hallaba en proceso de mutación y devenir: no se trataba del mismo sujeto al comenzar el viaje que al terminarlo, ni al escribir las notas originales que al momento de pulirlas y organizarlas para su publicación. El viaje aparecía, pues, como una dinámica que le interesaba, en esencia, por desencadenar una radical transformación subjetiva ${ }^{5}$. Esa misma función la iba a desempeñar, en sus textos posteriores, la guerrilla: el cronotopo esencial al que, en su obra teórica y narrativa, iba a otorgar la capacidad, nuclear en su proyecto político, de producir sujetos nuevos 6 .

En cualquier caso, esa aparente contradicción entre voluntad documental y punto de vista personal marcaba a fuego la forma en que el propio Guevara conceptualizaba su escritura. Efectivamente, la vinculaba recurrentemente a la captación visual, en un doble sentido que, por una parte, aludía a su carácter documental y de registro pero que, por otro, incidía en el carácter subjetivo de esa mirada. Se

\footnotetext{
${ }^{5}$ No se trataba de que el sujeto adquiriera un saber a lo largo del viaje, sino de que esta adquisición de saber que se supone a la experiencia viajera cambiaría para siempre la titularidad del sujeto que se hacía cargo de ella. Esto es, que la propia dinámica del viaje producía un sujeto nuevo, inexistente anteriormente y articulado en torno a elementos que antes no estaban presentes en él. Por ello, Guevara consagraba en su texto el nomadismo como forma de transformación continua: "Ahora sé, casi con una fatalista conformidad, que mi sino es viajar (...). Quizá algún día cansado de rodar por el mundo vuelva a instalarme en esta tierra argentina y entonces, si no como morada definitiva, al menos como lugar de tránsito hacia otra concepción del mundo, visitaré nuevamente y habitaré la zona de los lagos cordilleranos". Pueden hallarse reflexiones interesantes sobre la relación de Guevara con el viaje en Zygmunt (2013).

${ }^{6}$ Victoria García ha mostrado con brillantez la continuidad entre las dinámicas del viaje y la guerrilla en los textos de Guevara (García, 2015).
} 
Jaume Peris Blanes. Relatos para una revolución potencial...

servía, para ello, de la metáfora fotográfica, a través de la cual explicaba la compleja relación entre el acontecimiento y su representación.

No es este el relato de grandes hazañas impresionantes, no es tampoco meramente un 'relato un poco cínico'; no quiere serlo, por lo menos. El hombre, medida de todas las cosas, habla aquí por mi boca y relata en mi lenguaje lo que mis ojos vieron (...) mi boca narra lo que mis ojos le contaron.

En cualquier libro de técnica fotográfica se puede ver la imagen de un paisaje nocturno en el que brilla la luna llena y cuyo texto explicativo nos revela el secreto de esa oscuridad a pleno sol, pero la naturaleza del baño sensitivo con que está cubierta mi retina no es bien conocida por el lector, apenas la intuyo yo, de modo que no se pueden hacer correcciones sobre la placa para averiguar el momento real en que fue sacada. Si presento un nocturno créanlo o revienten, poco importa, que si no conocen personalmente el paisaje fotografiado por mis notas, difícilmente conocerán otra verdad que la que les cuento aquí (1992: 20).

La metáfora fotográfica habilitaba un doble eje semántico. En primer lugar, la idea de un registro mecánico que pudiera fijar una realidad en devenir en una imagen precisa. Guevara daba un singular sentido a esa idea, pues articulaba la captación visual al acto de narrar ('lo que mis ojos le contaron'): si la fotografía podía generar documentos de una realidad en transformación, la escritura podía ser el espacio de un cierto documentalismo narrativo ${ }^{7}$.

En segundo lugar, esa vocación documental contrastaba con dos características fundamentales de la fotografía. Por una parte, con la naturaleza situada de una imagen, que implica siempre un recorte, un encuadre y, por tanto, un punto de vista determinado sobre la realidad. Por otra, con el carácter maleable y manipulable de la imagen fotográfica, que mediante técnicas de procesado puede transformar la apariencia de la realidad de la que trata de dar cuenta. Dos consecuencias se derivaban de ello: la primera, el carácter esencialmente subjetivo del documento producido (basado en el 'baño sensitivo' de su autor); la segunda, el pacto de verdad que necesariamente debía validar el carácter documental del texto: "créanlo o revienten", pues no había más verificabilidad posible que la palabra de su autor.

Ese doble eje iba a cobrar una importancia monumental en el momento en que la escritura de Guevara pasó de hacerse cargo de una experiencia personal a representar una experiencia colectiva de gran impacto histórico. En el prólogo a sus Pasajes de la guerra revolucionaria otorgaba un propósito muy claro a su escritura: fijar los hechos y su desarrollo para que no se perdieran en las brumas de la memoria: "van pasando los años y el recuerdo de la lucha insurreccional se va disolviendo en el pasado

\footnotetext{
${ }^{7}$ En un momento de Pasajes de la guerra revolucionaria, Guevara contraponía la condición de la escritura como registro y generador de documentos con el carácter voluble y contingente de la memoria, al relatar la muerte de Calixto Morales, guerrillero y poeta, que "tenía toda la historia de la revolución, hasta el momento de la partida del Granma (...) como había poco papel en la Sierra, iba componiendo las décimas y aprendiéndolas de memoria, de modo que no nos quedaron recuerdos cuando una bala pusiera fin a su vida" ([1963]: 55).
} 
Jaume Peris Blanes. Relatos para una revolución potencial...

sin que se fijen claramente los hechos que ya pertenecen, incluso, a la historia de América" ([1963]: V). Pero, a la vez, Guevara insistía en el carácter limitado y precario de esa 'fijación de la realidad' y sus narraciones se acompañaban del llamamiento a otros protagonistas de los mismos acontecimientos que pudieran complementar el relato de la lucha guerrillera con todo aquello que el propio Guevara no hubiera tenido la oportunidad de conocer.

No es nuestro propósito hacer solamente esta historia fragmentaria a través de remembranzas y algunas anotaciones; todo lo contrario, aspiramos a que se desarrolle el tema por cada uno de los que lo han vivido.

Nuestra limitación personal, al luchar en algún punto exacto y delimitado del mapa de Cuba durante toda la contienda, nos impidió participar en combates y acontecimientos de otros lugares (...). Muchos supervivientes quedan de esta acción y cada uno de ellos está invitado a dejar también constancia de sus recuerdos para incorporarlos y completar mejor la historia ([1963]: $\mathrm{V})$.

Por una parte, pues, registro casi mecánico de la realidad. Pero, por otra, anclaje en la posición subjetiva y en la imposibilidad de una mirada global y definitiva sobre el acontecimiento ${ }^{8}$. La escritura testimonial de Guevara, por ello, se ofrecía como un proceso abierto, inacabado y que trataba de convocar otras voces en su seno. En última instancia, se estaba proponiendo una versión antiautoritaria de la escritura de la historia: sólo habría un relato veraz cuando todos los participantes contaran su versión particular, subjetiva y parcial, pero de un valor superior al de la historia tradicional, de la que esas visiones particulares estaban excluidas.

\section{Hacia una nueva cultura revolucionaria: ¿una cultura sin intelectuales?}

En esta última idea latía uno de los propósitos más firmes de Guevara, que estaba conectado con una nueva forma de entender la historia, la cultura y la sociedad: frente a las metodologías tradicionales de escritura de la historia, elaborada por intelectuales ligados al poder económico y social, proponía otra historia escrita por aquellos que vivieron y experimentaron los acontecimientos. Esa voluntad de poner en marcha una nueva concepción de la historia, no mediada por los intelectuales, no tenía que ver, únicamente, con un cambio del punto de vista de la representación, sino con una redefinición de la naturaleza del trabajo cultural en el interior de un proceso revolucionario.

\footnotetext{
${ }^{8}$ En sus crónicas testimoniales sobre la guerrilla en el Congo, insistiría en esta idea: "Como una norma general, norma que siempre he seguido, aquí solo se dice la verdad, al menos mi interpretación de los hechos, aunque esta pueda ser enfrentada por otras apreciaciones subjetivas o corregidas, si se deslizan errores en el relato de acontecimientos" (1999: 17).
} 
Jaume Peris Blanes. Relatos para una revolución potencial...

De hecho, esa idea conectaba perfectamente con un imaginario bien presente en Cuba desde el triunfo de la revolución. Ya en 1961, en sus famosas Palabras a los intelectuales, Fidel Castro había imaginado una nueva forma de escribir el pasado.

En días recientes nosotros tuvimos la experiencia de encontrarnos con una anciana de 106 años que había acabado de aprender a leer y escribir y nosotros le propusimos que escribiera un libro. (...) Creo que esta vieja puede escribir una cosa tan interesante como ninguno de nosotros podríamos escribirla sobre su época (...) ¿Quién puede escribir mejor que ella lo que vivió el esclavo? (Castro, 1961).

Dicho de otro modo: la revolución no podía aceptar las formas, metodologías y rutinas de la práctica intelectual y cultural burguesa. Por el contrario, debía reinventar los lugares desde los que se producían los discursos culturales y las representaciones institucionalmente legitimadas de la historia. La imagen de una anciana, antigua esclava, escribiendo sus memorias tras ser alfabetizada funcionaba, así, como una imagen utópica, al menos, en dos sentidos complementarios. Por una parte, situaba el empoderamiento de las clases populares y subalternas como el primer objetivo cultural de la revolución cubana; generar las condiciones para que aquellos colectivos que, hasta el momento, no habían podido hacer llegar su voz al espacio público en condiciones de legitimidad pudieran, por fin, hacerlo. Por otra parte, desprofesionalizaba el ejercicio de la cultura y de la historia, democratizando el lugar de enunciación que, hasta el momento, habían ocupado las clases letradas e intelectuales; de ese modo, imaginaba una sociedad en la que la figura del intelectual podía dejar de ser el mediador entre la experiencia social y su representación pública y una cultura que parecía ya no necesitar al intelectual como regulador de los discursos públicos.

Se trataba, en cualquier caso, de una concepción de la cultura coherente con la crítica a la distribución social del trabajo propia de una sociedad estratificada y dividida en clases ${ }^{9}$. La modernidad capitalista se había caracterizado por la separación y especialización de las esferas productivas; en ese proceso, la práctica intelectual y artística se había separado definitivamente de otras prácticas discursivas y públicas (como la política, la burocracia estatal o la jurídica) y había afrontado un proceso de profesionalización y especialización progresivas que se halló en el origen de los debates sobre la autonomía estética que caracterizaron a algunas culturas latinoamericanas de la primera parte del siglo $X X^{10}$. En ese sentido, la figura del intelectual moderno, independientemente de su orientación política -

\footnotetext{
${ }^{9}$ A ello aludía Guevara en su discurso sobre el trabajo voluntario: "El trabajo voluntario se convierte entonces en un vehículo (...) para preparar el camino hacia una nueva etapa de la sociedad, una nueva etapa de la sociedad donde no existirán las clases y, por lo tanto, no podrá haber diferencia ninguna entre trabajador manual o trabajador intelectual, entre obrero o campesino" ([1964]: 334).

${ }^{10}$ Los modernismos latinoamericanos fueron, sin duda, respuestas culturales de primer orden a estos procesos. Puede consultarse un análisis detallado en la obra de Julio Ramos (1989) y Sonia Mattalia (1998).
} 
Jaume Peris Blanes. Relatos para una revolución potencial...

a menudo muy crítica con él-, surgió de este proceso de profesionalización y especialización y de la lógica capitalista de la distribución social del trabajo que contribuyó a la estratificación social propia de los procesos de modernización latinoamericanos, basados en un desarrollo desigual y combinado.

No era ilógico, por tanto, que en el momento en que la revolución cubana se planteaba rediseñar desde parámetros nuevos la distribución del trabajo y la riqueza repensara también la distribución de los lugares de enunciación social y la centralidad que, en ellos, estaba desempeñando la intelectualidad. En "El socialismo y el hombre en Cuba" (1965) Guevara arremetía duramente no sólo contra el trabajo realizado por los intelectuales, sino contra la figura del intelectual y del artista en sí, entendida como remanente de una sociedad basada en la distribución social del trabajo:

La culpabilidad de muchos de nuestros intelectuales y artistas reside en su pecado original; no son auténticamente revolucionarios. Podemos intentar injertar el olmo para que dé peras; pero simultáneamente hay que sembrar perales. Las nuevas generaciones vendrán libres del pecado original. Las probabilidades de que surjan artistas excepcionales serán tanto mayores cuanto más se haya ensanchado el campo de la cultura y la posibilidad de expresión. Nuestra tarea consiste en impedir que la generación actual, dislocada por sus conflictos, se pervierta y pervierta a las nuevas (530).

La argumentación de Guevara no dejaba lugar a dudas: intelectuales y artistas estaban marcados por un 'pecado original' que atañía a su propia naturaleza social. Nacidos, criados y profesionalizados en una sociedad burguesa, para Guevara el hecho de continuar siendo artistas o intelectuales parecía confirmar que no habían roto, en esencia, con ella. En pocas palabras, señalaba que los intelectuales del momento eran exponentes de una función social caduca, propia de las sociedades prerrevolucionarias ${ }^{11} \mathrm{y}$ que, por tanto, llevaban incorporados valores incompatibles con la sociedad revolucionaria y que podían, incluso, pervertir a las nuevas generaciones libres de ese 'pecado original'.

La voluntad de Guevara de una necesaria superación de la idea de intelectual tenía lugar en un ambiente político de creciente desconfianza en las capacidades de la cultura para producir efectos realmente revolucionarios. Esa tendencia, que sin duda la figura y los escritos de Guevara alentaron, dio lugar a la emergencia de un imaginario que Gilman ha llamado 'anti-intelectual'12, en el que las

11 Esa idea, iba a aparecer, más desarrollada y definida, en los debates sobre el rol del intelectual que tuvieron lugar en la segunda mitad de los años sesenta, con creciente virulencia en Cuba. En el Congreso Cultural de la Habana, celebrado en enero de 1968, poco tiempo después de la muerte del Che en Bolivia, planteaba León Rozitchner: "la dependencia forma parte de nuestros propios hábitos mentales y está profundamente arraigada en nosotros. (...) Nuestras ideas, nuestros modelos de pensamiento, nuestra racionalidad en suma, aparecen como la extensión de la racionalidad dominadora del sistema de dependencia que, desde los países centrales, se prolongan en cada uno de nosotros y entra a formar parte de nuestro modo subjetivo, espontáneo y separado, de pensar la realidad” (Rozitchner, 1968: 16).

12 Sobre el imaginario antiintelectual en Cuba y la apertura de nuevos lugares de enunciación cultural ver también Peris Blanes (2012). 
Jaume Peris Blanes. Relatos para una revolución potencial...

competencias específicas del escritor -y de los profesionales de la cultura- fueron seriamente cuestionadas como modo efectivo de intervención social (2003: 143-188).

Tres elementos estructuraban ese creciente imaginario antiintelectual. En primer lugar, la contraposición entre la eficacia revolucionaria del hombre de acción y del hombre de letras, que iba a caer indefectiblemente del lado de las diferentes formas de la lucha política práctica y que iba a servir para desacreditar la acción cultural -entendida como espacio diferenciado y autónomo- como lugar de desarrollo revolucionario ${ }^{13}$. En segundo lugar, la redefinición del lugar de los intelectuales en la nueva distribución del trabajo: de poetas a alfabetizadores, de creadores libres a funcionarios del Estado, de ratas de biblioteca a cortadores de caña; en la nueva sociedad, la cultura no podía ser un espacio laboral separado y por tanto sus trabajadores -los intelectuales- no debían sustraerse del todo a las exigencias del proceso revolucionario ${ }^{14}$. En tercer lugar, y derivado de los anteriores, la posibilidad misma de prescindir de los intelectuales, artistas y científicos sociales -profesionales de la cultura y la investigación social- como mediadores entre la población, la historia y la cultura. Es decir, la posibilidad de construir una cultura sin intelectuales, una Historia sin historiadores o una literatura sin escritores.

Sería el propio Fidel Castro, en su conocido discurso en la Universidad de La Habana en agosto de 1967, quien formulara de un modo más nítido esa posibilidad, identificando intelectualidad con élite social y contraponiendo la cultura de los intelectuales -propia de una sociedad estratificada, en la que el pueblo se halla excluido como sujeto de ella- con la de un pueblo empoderado y, por ello capaz de producir su propia cultura, su propia historia y su propia teoría política.

No sé cuántas veces ustedes se han preguntado cómo en la práctica se puede llegar a una distribución comunista de los bienes que el hombre produce. Sobre eso hay muchas teorías, (...) y mucha bobería (RISAS). Ahora nosotros tenemos que escribir la nuestra. Esa teoría nuestra no la va a escribir un científico, no la va a escribir una élite intelectual (...). La cultura dejará de ser cuestión de élite cuando le pertenezca a todo el pueblo (Castro, citado Hernández 2009: 45).

\footnotetext{
13 Tras su muerte, la glorificación de la figura de Guevara iba a consagrar hasta tal punto la imagen del guerrillero heroico que ninguna actividad intelectual iba a resistir la comparación con la magnitud de la obra guevariana. En abril de 1967, pocos meses antes de morir, en su mensaje a la Tricontinental en el que llamaba a la insurrección armada global contra el imperialismo, Guevara había dejado bien claro su posición ante la eficacia del lenguaje como elemento de transformación social y de combate: "En el momento de la lucha, la forma en que se hacen visibles las actuales diferencias constituye una debilidad; (...) querer arreglarlas mediante palabras es una ilusión” (1967: 100). En un texto audaz, Benedetti (1968) trataría de explorar 'las relaciones entre el hombre de acción y el intelectual' para tratar de hallar una cierta conciliación entre ambos.

${ }^{14}$ Una nítida explicación ofrecía Ambrosio Fornet al respecto: "Cuando los intelectuales de un país en revolución exigimos de los demás responsabilidades concretas es porque hemos asumido las nuestras y estamos dispuestos a dar cuenta de nuestros actos. No hablo solo de nuestras responsabilidades cívicas. Como intelectuales de un país subdesarrollado en revolución, alfabetizar, aprender el manejo de las armas, cortar caña, ya forman parte de nuestros deberes elementales; carentes de cuadros intermedios estamos obligados, además, a servir de intermediarios entre nuestra obra y nuestro público; el poeta ha comprendido que para que ese hermoso y extraño poema que ahora escribe en silencio sea repetido mañana por las calles, él mismo tiene que convertirse en maestro, divulgador y funcionario cultural” (Fornet, 1968: 27).
} 
Jaume Peris Blanes. Relatos para una revolución potencial...

Esa idea germinal de una cultura emancipada de la intelectualidad tenía lugar, como es sabido, en un espacio político que había apostado por una fuerte institucionalidad cultural que, desde el triunfo de la revolución, había desencadenado una incomparable efervescencia cultural y literaria (Quintero Herencia, 2002). La creación del Consejo Nacional de Cultura, la Casa de las Américas, el periódico Revolución, la UNEAC, el ICAIC y otras instituciones culturales permitió la emergencia de un debate rico y polimórfico atravesado por posicionamientos estéticos muy encontrados y heterogéneos, en los que la figura del intelectual de izquierdas fue fundamental. En ese sentido, las políticas culturales de la revolución en la década de los sesenta estuvieron marcadas por fenómenos como la eclosión de un poderoso movimiento editorial y universitario, el estallido de la canción protesta, las polémicas intelectuales vinculadas Lunes de Revolución y el Congreso Cultural de La Habana y la consagración de las más diversas tendencias artísticas ${ }^{15}$. No sería hasta 1971, con el Primer Congreso de Educación y Cultura, que las políticas culturales cubanas apostarían por un nuevo y único tipo de discurso y de práctica cultural, imperantes durante toda la década de los setenta (Fornet, 2013). No se trata, pues, de que las autoridades revolucionarias acabaran con el apoyo a las prácticas culturales ni al trabajo intelectual, ni mucho menos: se trata de que ese apoyo convivió con un discurso -ciertamente oscilante, con sus picos de intensidad en los años finales de la década de los sesenta- que lo cuestionaba y que de ese modo marcaba sus límites -'dentro de la revolución todo, fuera de la revolución, nada'-.

Es más, la presencia de ese discurso antiintelectual, que imaginaba otra cultura posible liberada de la presencia de la élite intelectual, permitía conceptualizar a las prácticas intelectuales y artísticas del momento como el efecto de un desajuste histórico: el de una revolución política que todavía se expresaba con las formas y prácticas culturales propias de una sociedad prerrevolucionaria. A ello se refería Guevara, en "El socialismo y el hombre en Cuba", con un razonamiento que vinculaba al nuevo sujeto que la revolución debía crear -el Hombre Nuevo- con las prácticas culturales del futuro, imposibles de llevar a cabo por los intelectuales imbuidos de una concepción prerrevolucionaria de la cultura.

Falta el desarrollo de un mecanismo ideológico-cultural que permita la investigación y desbroce la mala hierba (...) la necesidad de la creación del hombre nuevo, que no sea el que representa las ideas del siglo XIX, pero tampoco las de nuestro siglo decadente y morboso. El hombre del siglo XXI es el que debemos crear, aunque todavía es una aspiración subjetiva y no sistematizada. (...) Ya vendrán los revolucionarios que entonen el canto del hombre nuevo con la auténtica voz del pueblo (Guevara [1965]: 530).

Ese fragmento abría un interrogante esencial. Si la cultura verdaderamente revolucionaria -aquella que prescindiría del intelectual como trabajador especializado y sería creación del pueblo- dependía del advenimiento de ese Hombre Nuevo que estaba por llegar, ¿qué podía hacer la generación actual,

\footnotetext{
${ }^{15}$ Una argumentación contrastada en ese sentido puede hallarse en la intervención de Luisa Campuzano en el debate sobre el premio testimonio de Casa de las Américas publicada en este mismo número especial.
} 
Jaume Peris Blanes. Relatos para una revolución potencial...

portadora de ese 'pecado original' denunciado por Guevara pero con la vocación irrenunciable de servir culturalmente a la revolución?

\section{¿Escrituras de transición?}

En este periodo de construcción del socialismo podemos ver al hombre nuevo que va naciendo. Su imagen no está acabada; no podría estarlo nunca ya que el proceso marcha paralelo al desarrollo de formas económicas nuevas.

Guevara. "El socialismo y el hombre en Cuba" ([1965]: 373)

Señala Claudia Gilman que el razonamiento anterior dio lugar a lo que podría llamarse un 'mito de la transición”: "el mito de la transición puede considerarse una ficción a través de la cual se tramitó simbólicamente la brecha entre la realidad y las expectativas puestas en ella" (2003: 150-151). Pero lo importante es que esta idea no aludía sencillamente a una transición económica y social entre el sistema capitalista y el socialismo, sino sobre todo a una transición en la conciencia y al surgimiento de una nueva subjetividad. Por ello, la generación nacida en el mundo prerrevolucionario, cuyas mentes se hallaban irremediablemente colonizadas por el capitalismo pero cuya voluntad era romper con él, podía pensarse como una generación de transición que voluntariamente debería destruir las bases del mundo en que habían crecido para que ese nuevo sujeto limpio del 'pecado original' pudiera por fin emerger.

La mejor formulación de ese mito fue, como señala la propia Gilman, el poema de Roberto Fernández Retamar “Usted tenía razón, Tallet, somos hombres de transición”, en el que, en respuesta a Tallet, un poeta de la generación anterior, Fernández Retamar establecía un sistema de dicotomías en relación a las cuales se definía 'entre ellas' para terminar afirmando "Y porque después de todo, compañeros, quién sabe / si solo los muertos no son hombres de transición (1970:117). ${ }^{16}$ El sujeto poético definía su lugar entre los blancos y los negros, entre los ricos y los pobres y, en definitiva, entre el pasado que todavía no había dejado de pasar y el futuro que todavía no había llegado. El ‘entre’ dos

\footnotetext{
${ }^{16}$ Paco Urondo dialogaba con él en el poema ‘Solicitada', en que se desarrollaba la idea del poeta como hombre de transición: "Siempre los poetas fueron, en efecto, hombres de/ transición, Roberto / Fernández Retamar; porque, realmente, si un/ poeta, amigo / mío, no ve las transiciones que saltan a su/ alrededor como brotes de lava humeante, mejor/ que deje de serlo, ceda ese guiso perfumado a otros/ olfatos más perceptivos.

(...) Ya/ no soy / de aquí; apenas me siento una memoria / de paso. Mi confianza se apoya en el/ profundo/ desprecio/ por este mundo desgraciado. Le daré/ la vida para que nada siga como está”.
} 
Jaume Peris Blanes. Relatos para una revolución potencial...

mundos, pues, como característica esencial de esa subjetividad en pugna entre la remanencia de lo viejo y la emergencia de lo nuevo ${ }^{17}$.

No hay duda de que el propio Guevara fue el principal alentador teórico de este imaginario transicional. En su texto 'El socialismo y el hombre en Cuba' trató de sistematizar la transición al socialismo conceptualizándola como un proceso de construcción de una nueva subjetividad. No por casualidad este fue el texto en que más desarrolló Guevara la problemática cultural, por su estrecha relación con la conciencia y su modelización.

De entrada, Guevara definía dos modos diversos de construcción subjetiva. Por una parte, el del capitalismo, basado en el mito de Rockefeller y el selfmademan, que actúa sobre el individuo "sin que éste se percate", mostrándole un camino de escollos que, aparentemente, una persona con buenas cualidades podría llegar a superar. Pero se trataría, claro, de una "carrera de lobos; solamente se puede llegar sobre el fracaso de otros” ([1965]: 371), lo que habilitaría una lógica subjetiva de la competitividad, el aislamiento y la lucha por el beneficio privado frente al de los demás. Por otra parte, en el socialismo el incentivo fundamental debía ser el sentimiento de estar contribuyendo al beneficio de la comunidad: frente a los incentivos materiales de la subjetivación capitalista, proponía incentivos morales como herramienta para alcanzar una nueva subjetividad socialista. Sin embargo, Guevara señalaba que la nueva sociedad en formación tenía que competir muy duramente con el pasado, lo que se hacía sentir “en la conciencia individual, en la que pesan los residuos de una educación sistemáticamente orientada al aislamiento del individuo" ([1965]: 371) y a la mercantilización de todas las relaciones sociales. Por ello, avisaba:

Persiguiendo la quimera de realizar el socialismo con la ayuda de las armas melladas que nos legara el capitalismo (...) se puede llegar a un callejón sin salida. (...) Entre tanto, la base económica adaptada ha hecho su trabajo de zapa sobre el desarrollo de la conciencia. Para construir el comunismo, simultáneamente con la base material hay que hacer el hombre nuevo ([1965]: 372).

La conciencia aparecía, pues, como un espacio de lucha entre las bases ideológico-materiales de la sociedad pasada y una emergente forma de ser liberada de ellas: "el cambio no se produce automáticamente en la conciencia, como no se produce tampoco en la economía. Las variaciones son lentas y no son rítmicas; hay periodos de aceleración, otros pausados e incluso retroceso" ([1965]: 376). En ese espacio de lucha entre lo viejo y lo nuevo, dos elementos aparecían como centrales en la

17 Escribía Claudia Gilman al respecto: "El entre indica una circunstancia espacial que significa pasaje, traslación y movimiento. En consecuencia, los hombres del entre tienen un tipo de pensamiento doble, a un tiempo arraigado en lo que fue y también profético de lo que vendrá; incómodo con lo familiar y deseante de lo desconocido; desembarazado de lo viejo y celebración de lo nuevo. El entre es movimiento centrífugo, orientación hacia un otro que se integre al nosotros, o, mejor, un irse transformando en otro" (Gilman, 2003: 153). 
Jaume Peris Blanes. Relatos para una revolución potencial...

adquisición de una "total conciencia de su ser social" (376): por una parte, una nueva actitud libre y responsable ante el trabajo, que ya no sería más una forma de dominación y expropiación de la vida; por otra, la expresión de la propia condición humana a través de la cultura y el arte ${ }^{18}$.

En este texto fundamental, pues, Guevara otorgaba una función nuclear a la cultura y al arte como elementos esenciales del proceso de liberación social que iba a dar lugar a la emergencia del hombre nuevo. ¿Como conciliar, pues, sus críticas al 'pecado original' de los intelectuales con esta glorificación de lo artístico como proceso liberador? ${ }^{19}$ Guevara parecía establecer una diferenciación implícita entre una situación social -la que debía producir la revolución- en la que los trabajadores y hombres comunes fueran a la vez productores de arte y cultura -y por tanto, fueran capaces de 'expresar su condición humana' a través de ellos- y otra, que constituía el objeto de sus críticas, en la que los trabajadores se reducían a meros consumidores de una cultura escrita por intelectuales y productores profesionalizados de lo artístico. Es por ello que su texto suponía un ataque durísimo a la cultura entendida como espacio de consumo estético, identificando los usos comunes de la experiencia estética con la afirmación del individualismo como principio social:

Desde hace mucho tiempo el hombre trata de liberarse de la enajenación mediante la cultura y el arte. Muere diariamente las ocho y más horas en que actúa como mercancía para resucitar en su creación espiritual. Pero este remedio porta los gérmenes de la misma enfermedad: es un ser solitario el que busca comunión con la naturaleza. Defiende su individualidad oprimida por el medio y reacciona antes las ideas estéticas como un ser único cuya aspiración es permanecer inmaculado. Se trata sólo de un intento de fuga ([1965]: 377).

El problema es que Guevara no daba una alternativa clara a ese modelo de funcionamiento cultural, probablemente porque el propio aparato conceptual del que se servía no bastaba para articular esa nueva cultura que, en sus escritos, aparecía bajo el signo de lo potencial. Las alusiones fragmentarias y desorganizadas a ese modo cultural por venir permitían pensar, sin embargo, en una cultura emancipada de la distribución social del trabajo, desprofesionalizada, sin diferenciación entre los agentes de producción y de consumo. Una cultura, pues, horizontalizada y que acompañara un proceso radical de

\footnotetext{
18 “Todavía es preciso acentuar su participación consciente, individual y colectiva, en todos los mecanismos de dirección y producción (...) así logrará la total conciencia de su ser social, lo que equivale a su realización plena como cultura humana, rotas las cadenas de su enajenación. Esto se traducirá concretamente en la reapropiación de su naturaleza a través del trabajo liberado y la expresión de su propia condición humana a través de la cultura y el arte” ([1965]: 375-6).

${ }^{19}$ Se trataba de una contradicción en la que Guevara incurría recurrentemente, quizás por la dificultad, precisamente, de definir una práctica social potencial -la expresión artística del hombre nuevo- con el léxico y el aparato conceptual propio de la sociedad que se trataba de superar: 'arte' y 'cultura', que remitían a prácticas diferenciadas y autónomas e 'intelectual', que refería a un profesional de estas prácticas. En ese sentido, los propios textos teóricos de Guevara -también los narrativos, como se verá a continuación- constituyeron un espacio de lucha entre la emergencia de una nueva concepción de la expresión cultural y la permanencia de concepciones propias de la sociedad que pretendía superar.
} 
empoderamiento que hiciera del revolucionario -el trabajador, el guerrillero, el hombre común ${ }^{20}$ - el sujeto, y no solo el objeto, de una nueva enunciación cultural. A ello se refería cuando aludía a un nuevo "mecanismo ideológico-cultural" con el que pudiera entonarse "el canto del hombre nuevo con la auténtica voz del pueblo" ([1965]: 530).

En buena medida, los textos narrativos de Guevara suponían un intento incipiente y no exento de contradicciones de dar forma a ese nuevo mecanismo ideológico-cultural. Como se verá más adelante, ponían en el centro de la representación el proceso de transición de la conciencia revolucionaria y tematizaban insistentemente la emergencia en la guerrilla de ese nuevo sujeto que llamó Hombre Nuevo. Pero además, podemos considerar que constituían, en sí, escrituras de transición, ya que se situaban en ese lugar intersticial que mediaba entre la destrucción de las formas culturales tradicionales, propias de la sociedad prerrevolucionaria, y la emergencia de nuevas lógicas culturales, que expresaran una subjetividad plenamente revolucionaria. En ese espacio intersticial, los textos de Guevara constituían un espacio de tensión entre un nuevo modelo de escritura, alejado de las categorías estéticas y narrativas burguesas, y el remanente de una idea de la literatura propia del mundo que había quedado atrás, pero de la que sus textos no podían desembarazarse del todo.

Un signo de esa tensión lo constituye, sin duda, la ambivalencia ante el 'oficio' de escritor que emerge en declaraciones privadas y públicas de Guevara. Si bien, como hemos visto, en 'El socialismo y el hombre en Cuba' cuestionaba la capacidad de los profesionales de la escritura para expresar valores y crear lenguajes realmente revolucionarios, en otros textos mostraba una cierta fascinación por una figura propia del mundo social que trataba de derribar. En una conocida carta a Ernesto Sábato de 1960, se refería así al escritor argentino: “Ud. poseedor de lo que para mí era lo más sagrado del mundo, el título de escritor" ([1960b]: 676). Pero esa sacralización habría sido sustituida, en el curso de la revolución, por una posición diferente, no exenta de ironía:

Esta carta ha sido un poco larga y no está exenta de esa pequeña cantidad de pose que a la gente tan sencilla como nosotros le impone, sin embargo, el tratar de demostrar ante un pensador que somos también eso que no somos: pensadores ([1960b]: 680).

Dos movimientos, pues, en uno: por una parte, constatación de una fascinación pretérita pero todavía destacable, ante el oficio de escritor y de pensador ${ }^{21}$; por otra, falsa humildad de quien ensaya un

\footnotetext{
${ }^{20}$ Se utiliza el masculino porque en la conceptualización guevariana se expresa de ese modo, sin otorgar una gran relevancia al lugar de las mujeres en ese proceso de transformación subjetiva y social. Se trata, sin duda, de un aspecto a tener en cuenta, que merecería ser estudiado en profundidad y contextualizado en los diversos paradigmas revolucionarios de la época.

${ }^{21}$ En carta al poeta León Felipe se definía como poeta fracasado: ““El otro día asistí a un acto de gran significación para mí. La sala estaba atestada de obreros entusiastas y había un clima de hombre nuevo en el ambiente. Ma afloró una gota del poeta fracasado que llevo dentro y recurrí a Ud., para polemizar a la distancia; le ruego que así lo interprete” ([1964b]: 690).
} 
Jaume Peris Blanes. Relatos para una revolución potencial...

nuevo modelo cultural desprofesionalizado, produciendo conceptos e ideología sin ser pensador, pero situándose en un lugar de igualdad y competencia conceptual con los pensadores profesionales ${ }^{22}$.

Esa tensión ha acompañado desde su publicación a los textos narrativos de Guevara, que han sido recurrentemente leídos desde paradigmas muy diferentes. Fernández Retamar relató, al respecto, una anécdota jugosa, ocurrida en 1962, cuando junto a Nicolás Guillén visitó a Guevara para que autorizara la publicación de Pasajes de la guerra revolucionaria:

Cuando le informamos de nuestro propósito, el Che estuvo de acuerdo. Hablamos después de otras cosas, y de repente, para mi sorpresa, Guillén sacó un modelo de ingreso en la UNEAC [Unión Nacional de Escritores y Artistas de Cuba], se lo dio, y le pidió que lo llenara. El Che, no obstante admirar mucho a Nicolás, rehusó llenarlo, diciéndole que no se consideraba escritor. Tercié en la conversación explicándole que seguramente Nicolás no pensaba, al hacerle la solicitud, en sus versos, que al parecer el propio Guevara no apreciaba demasiado, sino en textos como los que nos habían llevado allí, y donde él se revelaba un evidente escritor, si bien no un escritor al uso. Pero tampoco mi argumentación lo hizo variar su criterio (Fernández Retamar, 1997: 109).

Como puede verse, desde el principio los Pasajes... fueron el objeto de una disputa valorativa. Mientras Guevara los integraba en su proyecto de pedagogía revolucionaria, la comunidad intelectual apostaba por su lectura desde una clave literaria, que no necesariamente estaba reñida con lo anterior, pero que situaba el valor del texto en un horizonte estético que el mismo Guevara había tratado de evitar $^{23}$. El propio Fernández Retamar, en un artículo temprano de 1962 -cuando las crónicas se habían publicado en revistas y diarios, pero no recogidas en libro- lo catalogaba de un "escritor de primer orden” y anunciaba la aparición, en ellas, de "una nueva literatura, caracterizada por su despreocupación de toda moda literaria, y su apego escueto, y por lo mismo conmovedor, al hecho real” (1962).

Buena parte de la literatura crítica de las décadas siguientes iba a profundizar en el valor literario de los textos narrativos de Guevara, aparentemente opacado por su indudable valor político ${ }^{24}$. Independientemente del valor de esas aportaciones, había una cierta contradicción en este gesto: si en la

${ }^{22}$ La explicación de Guevara sobre su renuncia a elaborar una teoría ideológica de la revolución cubana merece consignarse: “Así estamos ahora hablando un lenguaje que es también nuevo, porque seguimos caminando mucho más rápido que lo que podemos pensar y estructurar nuestro pensamiento, estamos en un movimiento continuo y la teoría va caminando muy lentamente. (...) Por eso tengo miedo de tratar de describir la ideología del movimiento; cuando fuera a publicarla, todo el mundo pensaría que es una obra escrita muchos años antes" ([1960b: 680).

${ }^{23}$ Un gesto curioso y revelador fue el de Julio Cortázar, quien en su relato ‘Reunión’ reescribió las crónicas de Guevara desde una perspectiva estética totalmente diferente a la que caracterizaba a los textos originales. He analizado detalladamente la reescritura de Cortázar y el conflicto de poéticas que implicaba en Peris Blanes (2014).

${ }^{24}$ El propio Fernández Retamar señala las contribuciones a este respecto de Pogolotti (1968), Kulteischiskovsk y Ospovat (1977), Portuondo (1981) y Diana Iznaga Beira ((1988). La introducción de Cintio Vitier a las Notas de viaje (1992) supuso un salto de calidad en la recepción literaturizada de los textos documentales de Guevara. 
propuesta de Guevara se hallaba una crítica a la figura del escritor profesional, a la especialización discursiva y a los valores estéticos tradicionales -por considerar que traducían al plano cultural la lógica de la estratificación y separación social- estas lecturas reinscribían sus textos en una figuración autorial que se legitimaba por criterios estéticos y por su competencia técnica en el uso de recursos literarios.

Se trataba, no obstante, de una contradicción en la que los propios textos de Guevara caían constantemente, incorporando descripciones y pasajes fuertemente literaturizados, que daban cuenta de una 'voluntad de estilo' innegable. Frente al despojamiento de la mayoría de sus crónicas, en otras podían leerse fragmentos de este calado:

La luna llena se recorta sobre el mar y cubre de reflejos plateados las olas. Sentados sobre una duna, miramos el continuo vaivén con distintos ánimos: para mí fue siempre el mar un confidente, un amigo que absorbe todo lo que cuenta sin revelar jamás el secreto confiado y que da el mejor de los consejos (1992: 19).

El camino serpentea entre los cerros bajos que apenas señalan el comienzo de la gran cordillera y va bajando pronunciadamente hasta desembocar en el pueblo, tristón y feúcho, pero rodeado de magníficos cerros poblados de una vegetación frondosa (1992: 28).

Quedamos en tierra firme, a la deriva, dando traspiés, constituyendo un ejército de sombras, de fantasmas, que caminaban como siguiendo el impulso de algún oscuro mecanismo psíquico (2002: 4).

Como puede verse, se trata de fragmentos saturados de rasgos literarios, tanto en la elaboración metafórica como en la construcción escénica, que dan un cierto vuelo literario a sus crónicas, especialmente a las de sus viajes de juventud pero también, aunque en menor medida, a las de la guerrilla. Aunque no se trate de su tono general, voluntariamente anti-retórico, la presencia recurrente de estos impulsos indica algo esencial en ellos: que su aspiración de construir ese nuevo mecanismo ideológico cultural que había de ser la voz del hombre nuevo se disputaba el espacio de la escritura con una concepción mucho más tradicional de la literatura, que le llevaba a incorporar elementos estetizantes que prestigiaran literariamente sus escritos. Se trataba, pues, como ya se ha dicho, de una escritura de transición, que incorporaba en su propia factura verbal las contradicciones y tensiones de esa conciencia en transformación de la que trataba de dar cuenta. 
Jaume Peris Blanes. Relatos para una revolución potencial...

\section{Experiencia, pedagogía revolucionaria y emulación}

En la actitud de nuestros combatientes se vislumbraba al hombre del futuro Guevara, [1965]: 368.

En 1960 Guevara publicó su primer libro, que iba a tener un impacto extraordinario en las prácticas revolucionarias que, en los años siguientes, se extenderían por toda América Latina: La guerra de guerrillas, dedicado a Camilo Cienfuegos, manual en el que "se sintetizan nuestras experiencias guerrilleras, porque son el producto de la vida misma" ([1960]: 27). No se trataba, pues, de un texto narrativo, sino de un ensayo práctico, en el que la experiencia vivida en la lucha guerrillera servía como material de base para una serie de conclusiones de alcance más o menos general sobre la práctica de la guerrilla y los modos posibles de encarar un proceso revolucionario.

En febrero de 1961, Guevara comenzó a publicar una serie de textos breves, por lo general bajo el título colectivo de Pasajes de nuestra guerra revolucionaria, en la revista del ejército Verde Olivo, que en mayo 1963 serían editadas por primera vez con su título definitivo, Pasajes de la guerra revolucionaria, por la intermediación ya comentada de Fernández Retamar y Nicolás Guillén y que en ediciones posteriores se vería aumentada por otras crónicas y relatos nuevos ${ }^{25}$. Aunque se trate, pues, de dos textos de factura radicalmente distinta, La guerra de guerrillas y Pasajes de la guerra revolucionaria eran producciones prácticamente consecutivas, que obedecían a objetivos diversos pero que compartían una misma preocupación y un lugar similar dentro del proyecto de afianzamiento y extensión de la revolución que preocupaba a Guevara en aquellos años. En ese sentido, son textos que deben ser leídos de forma complementaria, pues supusieron dos intentos diferentes de socializar la enseñanza de la experiencia revolucionaria y ofrecerla públicamente como palanca y motor de nuevos procesos insurreccionales.

La guerra de guerrillas partía de una constatación básica: que la victoria armada de los revolucionarios cubanos frente a las fuerzas de Batista suponía "un modificador de viejos dogmas sobre la conducta de las masas populares de la América Latina” ([1960]:31) que demostraba la capacidad del pueblo para liberarse de un gobierno autoritario a través de la lucha guerrillera. En ese sentido, ya en sus primeras páginas ofrecía una de sus tesis principales: no era necesario esperar a que se dieran las condiciones objetivas para desencadenar un proceso revolucionario, sino que un foco insurreccional suficientemente consciente de su poder desestabilizador podía crearlas por sí mismo. Dos consecuencias mayores se derivaban de ello: por una parte, que la experiencia concreta ofrecía una enseñanza definitiva

\footnotetext{
${ }^{25}$ Las sucesivas ediciones de Pasajes... pasaron a incluir “Una revolución que comienza”, publicado originalmente en 1959 y algunas cartas del periodo de la contienda, anteriores por tanto a la publicación de las crónicas en Verde Olivo.
} 
Jaume Peris Blanes. Relatos para una revolución potencial...

de mayor calado que los tratados teóricos ${ }^{26}$; por otra, que las condiciones objetivas en las que se obcecaban los teóricos marxistas de la época y que habían pospuesto múltiples proyectos revolucionarios podían ser revertidas por las condiciones subjetivas generadas por el grupo guerrillero.

Buena parte de los razonamientos de La guerra de guerrillas surgían de esta doble constatación: de la experiencia vivida en la lucha podía derivarse una enseñanza vital para los procesos revolucionarios del por venir ${ }^{27}$. Así, "teorizar lo hecho, estructurar y generalizar esta experiencia para el aprovechamiento de otros, es nuestra tarea del momento" ([1960]: 33). Ese fue, sin duda, uno de los límites históricos de su ensayo, derivar las leyes científicas de la guerrilla de una experiencia muy particular, desatendiendo las condiciones políticas e históricas que hicieron posible su triunfo: "es esto un boceto, que transcribe lo que fue pasando en las distintas etapas de la guerra de liberación cubana, pero que siempre tiene aproximadamente un contenido universal" ([1960]: 94). Aunque en diferentes momentos Guevara matizara esa universalidad otorgada a una experiencia concreta ${ }^{28}$, lo cierto es que se trataba de una tendencia que atravesaba de lado a lado su argumentación y que justificaba la elevación de la experiencia guerrillera de Guevara a ejemplo a seguir en otros lugares y procesos.

En diferentes momentos de la argumentación aparecía esa idea del guerrillero como sujeto ejemplar de la revolución, introduciendo una lógica que sería fundamental en su proyecto político:

El guerrillero como reformador social, no solo debe constituir un ejemplo en cuanto a su vida, sino también debe orientar constantemente en los problemas ideológicos (...) Así, del producto de esta interacción del guerrillero con su pueblo, surge la radicalización progresiva que va acentuando las características revolucionarias del movimiento y le van dando una amplitud nacional ([1960]: 62).

Así pues: el guerrillero había de convertirse en ejemplo social para desencadenar un proceso de concientización en la población ${ }^{29}$. De ahí se desprendía la austeridad impuesta a los guerrilleros, de la

\footnotetext{
${ }^{26}$ Esa tesis fundamental fue desarrollada ampliamente en la carta, ya comentada, a Ernesto Sábato de 1961, en la que precisamente citaba a La guerra de guerrillas como el repositorio de enseñanzas sobre la revolución que ningún tratado teórico podría mejorar.

27 "En todos estos casos estamos hablando con la memoria de lo ocurrido en nuestra guerra de liberación" ([1960]: 89).

${ }^{28}$ Por ejemplo: "por razones de exposición, supondremos que nuestra experiencia tiene valor universal, pero recordando siempre que, al divulgarla, se está dejando, en cada momento, la posibilidad de que haya una nueva manera de hacerlo que convenga más a las particularidades del grupo armado de que se trate" ([1960]: 74) y también: "hay posibilidades de perfeccionar en sumo grado todas estas cosas; lo repito una vez más, es nuestra experiencia cubana la que habla por mí, nuevas experiencias pueden hacer variar y mejorar estos conceptos. Damos un esquema, no una biblia” ([1960]: 107).

${ }^{29}$ Muchos años después, en su experiencia en Bolivia, Guevara seguía insistiendo en ello: "Después de clase lancé una descarguita sobre las cualidades de la guerrilla y la necesidad de una mayor disciplina y expliqué que nuestra misión, por sobre todas las cosas, era formar el núcleo ejemplo, que sea de acero, y por esa vía expliqué la importancia del estudio, imprescindible para el futuro" ([1967]: 481).
} 
Jaume Peris Blanes. Relatos para una revolución potencial...

que el propio Guevara haría gala sistemáticamente ${ }^{30}$, y un concepto que iba a devenir central en el proyecto guevariano de extensión revolucionaria: la emulación. Efectivamente, las crónicas de Guevara sobre la guerrilla estaban repletas de escenas en que la emulación aparecía como un principio fundamental de la educación revolucionaria: entre otras cosas, proponía a los guerrilleros leer biografías de héroes del pasado y aspiraba a convertir las situaciones de asimetría entre los grupos guerrilleros en dinámicas emulativas ${ }^{31}$.

En su famosa intervención sobre el trabajo voluntario, titulada "Una nueva actitud ante el trabajo" ([1964]), Guevara integró en su proyecto de extensión y pedagogía revolucionaria el concepto de emulación. En ella desarrollaba una línea fundamental de su pensamiento político y el núcleo de su idea de cómo debía ser la transición del capitalismo al socialismo, que había de sostenerse en el paso de una experiencia del trabajo como alienación y degradación -en la que el trabajador no sería más que una mercancía más- al trabajo como alegría y realización humana, en la que el trabajador ya no estaría enajenado de su ser, pues su objetivo consciente y voluntario sería trabajar por el bien colectivo. En ese proceso, el trabajo voluntario -no remunerado materialmente, sino con incentivos morales- no debía valorarse solo "por la importancia económica que signifique en el día de hoy para el Estado; el trabajo voluntario fundamentalmente es el factor que desarrolla la conciencia de los trabajadores más que ningún otro" ([1964]: 334). Según Guevara, "el hombre que trabaja con esa nueva actitud se está perfeccionando" ([1964: 333).

Así, no se trataba únicamente de una transformación económica, sino de una herramienta para el desarrollo de la conciencia que debía preparar el camino hacia una nueva sociedad sin clases ${ }^{32}$, es decir, "una escuela creadora de conciencia (...) que nos permite acelerar el proceso de tránsito hacia el comunismo" ([1964]: 341). Y en esa dinámica de producción de nueva conciencia era en la que el concepto de emulación iba a desempeñar un papel crucial: aquellos trabajadores que asumían voluntariamente una carga excepcional de trabajo constituían un ejemplo magnético a ser emulado por sus compañeros.

\footnotetext{
30 "El guerrillero como elemento consciente de la vanguardia popular, debe tener una conducta moral que lo acredite como verdadero sacerdote de la reforma que pretende. A la austeridad obligada por difíciles condiciones de la guerra debe sumar la austeridad nacida de un rígido autocontrol que impida un solo exceso, un solo desliz, en ocasión en que las circunstancias pudieran permitirlo. El soldado guerrillero debe ser un asceta" ([1960]: 61).

31 "La vida nómada del guerrillero, en esta etapa, lleva a un gran sentido de la confraternidad con los compañeros, pero también, a veces, a peligrosas rivalidades entre grupos o pelotones. Si no se canalizan éstas para producir emulaciones beneficiosas, se corre el riesgo de fragmentar la unidad de la columna" ([1960]: 80).

32 "Nuestro trabajo, nuestro trabajo de combatientes de la producción, es hacer que la conciencia se desarrolle cada día más en esta vía por la cual transitamos” ([1964]: 336).
} 
Jaume Peris Blanes. Relatos para una revolución potencial...

Y ese tipo de emulación es lo que va haciendo como un juego, que se mejore, que se amplíe cada vez más la base de los trabajadores que participan en la construcción social conscientemente, porque cada hora que se da es una hora consciente ([1964]: 340).

La Emulación se estableció, pues, como concepto político, ligado al desarrollo de la conciencia y como disparador del empoderamiento ciudadano ${ }^{33}$. Y si los trabajadores voluntarios eran el ejemplo a emular por los el resto de los obreros, el guerrillero y la lucha insurreccional eran, sin duda, el ejemplo fundamental que debía ser emulado por los combatientes potenciales en otros lugares del mundo: "hemos dado el primer grito en América, hemos sido los actores de esta nueva época histórica para nuestro continente. Somos un ejemplo y tenemos responsabilidades de ejemplo" ([1962]: 151). Es decir, Guevara aspiraba a desencadenar dos lógicas emulativas simultáneamente: por una parte, en la construcción del socialismo cubano, una emulación interna que tomara como ejemplo a los trabajadores excepcionales que anunciaban una nueva actitud, solidaria y no mercantil, con el trabajo; por otra parte, en la internacionalización de las luchas guerrilleras, una emulación externa que, partiendo del ejemplo cubano, permitiera extender las luchas insurreccionales a lo largo de América Latina y del mundo entero.

La guerra de guerrillas se escribió, sin duda, con ese propósito. Pero su aspiración universalizadora le impedía detenerse en la descripción de situaciones concretas, en la puesta en escena de acciones y en el desarrollo narrativo de un colectivo en continua transformación. Y si algo podía desencadenar la emulación de guerrilleros futuros era precisamente el conocimiento detallado de las circunstancias, los detalles y las elecciones políticas y vitales que habían tenido que tomar, en el interior de la lucha insurreccional, los propios guerrilleros cubanos. Así, del mismo modo que Guevara recomendaba a sus soldados revolucionarios leer biografías de héroes del pasado ${ }^{34}$, habría que crear los textos capaces de convertirse, en el futuro, en el material de una emulación revolucionaria posible.

Los Pasajes de la guerra revolucionaria vinieron, en buena medida, a colmar ese vacío. Se publicaron, como se ha recalcado anteriormente, con el propósito explícito de fijar claramente los hechos que constituyeron la historia de la guerra revolucionaria cubana, en un momento en que estos comenzaban a caer en el olvido. En ese sentido, se trataba de textos que apuntaban aparentemente hacia el pasado, y al modo en que el presente podía alojarlo y darle sentido. Pero, en lo esencial, eran textos que trataban de crear las condiciones de un futuro revolucionario, que formaban parte de una pedagogía de la revolución y que, por ello mismo, y más allá de su reconstrucción del pasado reciente, eran textos que se abrían a un futuro potencial, el de la internacionalización de las luchas revolucionarias, en la que

\footnotetext{
${ }^{33}$ Es en ese sentido que, al distinguir oficialmente a los obreros más productivos, en un texto no por casualidad titulado "En homenaje a los premiados en la Emulación", advertiría: "Yo a estos compañeros no les diría que han rendido culto a la producción, sino más bien que han hecho un gran desarrollo de la conciencia política” ([1962]:137).

34 "Es conveniente que se lleve algún libro, intercambiable entre los miembros de la guerrilla, libros que pueden ser buenas biografías de héroes del pasado" ([1960]: 73).
} 
Jaume Peris Blanes. Relatos para una revolución potencial...

los guerrilleros del porvenir habrían de necesitar ejemplos que les sirvieran de guía política y sostén emocional.

\section{Hacia una nueva subjetividad: disciplina y narratividad}

El socialismo económico sin la moral comunista no me interesa. Luchamos contra la miseria, pero al mismo tiempo luchamos contra la alienación (...). Si el comunismo descuida los hechos de conciencia puede ser un método de repartición, pero deja de ser una moral revolucionaria.

Guevara en entrevista de Jean Daniel (Martínez Heredia, 2010: 83).

Como se ha visto, para Guevara el verdadero espacio de la revolución era la conciencia humana. El viaje y el trabajo voluntario, entre otros procesos, suponían dinámicas en las que, más que generar una transformación material, se producía una transformación radical de la subjetividad: "el personaje que escribió estas notas murió al pisar de nuevo tierra Argentina, el que las ordena y pule, 'yo, no soy yo’; por lo menos no soy el mismo yo interior (Guevara, 1992: 17-18)". La guerrilla participaba de esa misma lógica, pero llevada al extremo: más que una fuerza para tomar el poder político, Guevara la valoraba como una tecnología de la subjetividad, que producía en las personas que participaban en ella una transformación de gran radicalidad. Como señala Vezzetti comentando a Guevara, "en la configuración revolucionaria, la transformación del mundo y la del sujeto se implican mutuamente y se justifican en el horizonte de una mutación colectiva" $(2009,173)$. En su famosa carta a Sábato escribía:

La guerra nos revolucionó. No hay experiencia más profunda para un revolucionario que el acto de la guerra; no el acto aislado de matar, ni el de portar un fusil o el de establecer una lucha de tal o cual tipo, es el total del hecho guerrero, el saber que un hombre armado vale como unidad combatiente, $\mathrm{y}$ vale igual que cualquier hombre armado, $\mathrm{y}$ puede ya no temerle a otros hombres $\operatorname{armados}([1960 \mathrm{~b}]:$ 678).

¿Cómo representar esa fenomenal transformación subjetiva en textos que pudieran llegar a producir efectos de emulación social? Las crónicas contenidas en Pasajes de la guerra revolucionaria trataban de llevarlo a cabo, dándole una gran centralidad a escenas que condensaban argumentalmente esos procesos de transformación subjetiva. Un ejemplo de ello es la crónica “Alegría del Pío”, en la que Guevara introducía una escena breve pero esencial que trataba de capturar y metaforizar ese proceso de transformación subjetiva: confrontado a la elección entre las balas o el botiquín, decidía elegir las balas.

...en ese momento un compañero dejó una caja de balas casi a mis pies, se lo indiqué y el hombre me contestó con cara que recuerdo perfectamente, por la angustia que reflejaba, algo así como 'no es hora para cajas de balas', e inmediatamente siguió el camino del cañaveral (...). Quizás ésa fue la primera vez que tuve planteado prácticamente ante mí el dilema de mi dedicación a la 
Jaume Peris Blanes. Relatos para una revolución potencial...

medicina o a mi deber de soldado revolucionario. Tenía delante una mochila llena de medicamentos y una caja de balas, las dos eran mucho peso para transportarlas juntas; tomé la caja de balas, dejando la mochila para cruzar el claro que me separaba de las cañas ([1963]: 6).

De ese modo, Guevara representaba narrativamente la conversión del joven médico en soldado revolucionario: se trataba de la metaforización de un proceso interior, que dramatizaba un conflicto subjetivo y su resolución a través de una escena dilemática. Y apuntaba, de esa forma, al reto mayor al que se enfrentaban las crónicas guevarianas: poner en relato el proceso de transformación subjetiva que daba lugar a la emergencia del sujeto revolucionario.

Como en La guerra de guerrillas, Guevara daba a la experiencia concreta un rango de universalidad. Pero si en La guerra... la enseñanza derivada de ella aparecía en su desnudez conceptual sin referencia a la anécdota que la originaba, las crónicas de Pasajes... explicitaban el proceso de adquisición de ese saber general, a través de una lógica argumentativa en la que la descripción de una escena o secuencia era clausurada por una enseñanza derivada de ella: de esa forma, de las acciones del texto podía derivarse buena parte de la teoría bélica que, en otro registro, se había consignado en $L a$ guerra de guerrillas ${ }^{35}$. Ese tipo de estructura textual, que cruzaba elementos narrativos y argumentativos, permitía que, tras contar la historia del mayoral David, capturado por el ejército y torturado bárbaramente, Guevara decidiera que "nuestra misión es desarrollar lo bueno, lo noble de cada uno y convertir a todo hombre en revolucionario"([1963]: 68).

Roberto González Echevarría ha señalado cómo en la narrativa testimonial de los sesenta apareció un tópico narrativo fundamental que sin duda los Pasajes de Guevara contribuyeron a consolidar: el del proceso de conversión al credo revolucionario (1980: 250-52). Como señala con agudeza Silvia Maccioni, el concepto mismo de 'pasajes' aludía a una forma textual fragmentaria, pero también a un "proceso de la subjetividad que puede describirse como el tránsito, el movimiento que lleva de una condición en la que el sujeto está alienado de sí, hacia otra, en la que encuentra finalmente su condición verdadera" $(2013,35)$.

Efectivamente, la sucesión de anécdotas, acciones y escenas que componen Pasajes de la guerra revolucionaria se articulaba narrativamente a través de la transformación progresiva del grupo

\footnotetext{
35 Por ejemplo: "Pocos días antes habíamos derrotado a un grupo menor en número, atrincherado en un cuartel; ahora derrotábamos una columna en marcha superior en número a nuestras fuerzas y se pudo experimentar la importancia que tiene en este tipo de guerra liquidar las vanguardias, pues sin vanguardia no puede moverse un ejército" ([1963]: 20).
} 
Jaume Peris Blanes. Relatos para una revolución potencial...

guerrillero $^{36}$. Si algo dotaba de continuidad narrativa a esas acciones era el progresivo disciplinamiento colectivo en el sentido particular que Guevara daba a esta categoría y que aparecería perfectamente definida en su artículo de 1959 titulado explícitamente "Qué es un guerrillero".

La disciplina guerrillera es interior, nace del convencimiento profundo del individuo, de esa necesidad de obedecer al superior, no solamente para mantener la efectividad del organismo armado que está integrado, sino también para defender la propia vida. Esta disciplina informal muchas veces no se ve (...) sin embargo, el ejército de liberación fue un ejército puro donde ni las más comunes tentaciones del hombre tuvieron cabida; y no había aparato represivo, no había servicio de inteligencia que controlara al individuo frente a la tentación. Era su autocontrol el que actuaba. Era su rígida conciencia del deber y de la disciplina ([1959]: 154).

En buena medida, Pasajes ponía en relato el proceso de disciplinamiento interior -y también, claro, el disciplinamiento corporal que le acompañaba, que Guevara no llegaba a conceptualizar pero que aparecía tematizado en las crónicas- necesario para la transformación de un puñado de personas en un grupo revolucionario. Por ello, en las primeras crónicas, en las que se narraban los primeros meses de lucha guerrillera, abundaban escenas que apuntaban a una representación caótica y descontrolada del grupo guerrillero, falto de disciplina, control y el mínimo sentido organizativo necesario para llevar a cabo una guerra. En diferentes momentos se aludía a la incompetencia con respecto al uso del armamento y a su calidad y eficiencia ${ }^{37}$ : en una escena paradigmática, Guevara relataba cómo, tras un combate, había decidido portar como trofeo un casco del ejército batistiano:

La vanguardia nos oyó venir desde lejos y vio el grupo encabezado por uno que llevaba casco. Afortunadamente en ese momento se estaban limpiando las armas, y solamente funcionaba el fusil de Camilo Cienfuegos que disparó sobre nosotros, aunque inmediatamente comprendió su error; el primer disparo no dio en el blanco y el fusil automático se trabó impidiéndole seguir disparando. Este hecho demuestra el estado de tensión que teníamos todos ([1963]: 18).

La escena aludía a un descontrol total: el gesto infantil de Guevara que desencadenaba el ataque de Cienfuegos, el armamento inoperativo en su práctica totalidad, la impericia de Cienfuegos en el tiro y el trabado de su fusil tras el primer disparo... todo ello suponía un cuadro ridículo de ingenuidad, falta de precaución y desconocimiento de las técnicas elementales de organización militar que, en el contexto de

36 “En el texto del Che, son varios los pasajes que ocurren: de médico a guerrillero, de 'bisoño' a guerrillero veterano, de joven burgués a 'joven revolucionario', de hombre viejo a Hombre Nuevo. Y este recorrido complejo conduce por último a una zona de autenticidad en la que la verdad del sujeto queda revelada en toda su luminosidad. (...) De acuerdo con las leyes de la dialéctica, esta conversión al ideario de la Revolución por parte del guerrillero sería la contraparte necesaria de la transformación de la realidad objetiva" (Maccioni, 2013: 35-36).

37 "Se dieron órdenes de disparar nuestras viejas granadas de tipo brasileño; Luis Crespo tiró la suya, yo la que me pertenecía. Sin embargo no estallaron. Raúl Castro tiró dinamita sin niple y ésta no hizo ningún efecto" ([1963:16). A medida que avanzaba la evolución del grupo guerrillero, Guevara daba cuenta de su creciente fascinación por el armamento, directamente relacionada con su proceso de disciplinamiento: "a la noche llegaron las armas, para nosotros aquello era el espectáculo más maravilloso del mundo" ([1963]: 54). 
una lucha insurreccional, parecía abocar a un fracaso seguro. Sin embargo, progresivamente esas imágenes de un grupo desorganizado, descontrolado e infantiloide iban siendo sustituidas por las de un colectivo cada vez más cohesionado y eficaz: "daba gusto ver de nuevo a nuestra tropa con más disciplina, con mucha más moral, con cerca de doscientos hombres, algunas armas nuevas entre ellas. Finalmente se notaba que el cambio cualitativo de que hemos hablado estaba manifestándose en la Sierra Maestra. Existía un verdadero territorio libre” ([1963]: 75).

Guevara dedicaba una importante energía narrativa a representar ese ‘cambio cualitativo' que suponía la transformación colectiva del grupo guerrillero como efecto de su disciplinamiento. Una nítida representación de esa evolución se daba en los momentos en que la columna guevariana, ya muy curtida, se abría a la incorporación de grupos de nuevos guerrilleros:

En los pocos meses vividos en la Sierra, nos habíamos convertido en veteranos y veíamos en la nueva tropa todos los defectos que tenía la original del Granma: falta de disciplina, falta de acomodo a las dificultades mayores, falta de decisión, incapacidad de adaptarse todavía a esta vida (...) En estos días se notaba la diferencia enorme entre los dos grupos: el nuestro disciplinado, compacto, aguerrido; el de los bisoños, padeciendo todavía las enfermedades de los primeros tiempos ([1963]: 38).

Ese 'cambio cualitativo' constituía, pues, uno de los ejes de sentido que vertebraban el desarrollo narrativo del texto ${ }^{38}$. En él cobraba sentido la exaltación de los procesos disicplinarios, incluida la violencia contra los propios guerrilleros, como medio de acentuar ese cambio e impedir cualquier retroceso en la evolución colectiva: [Fidel] "anunció que tres delitos se castigarían con la pena de muerte: la insubordinación, la deserción y el derrotismo. La situación no estaba muy alegre en esos días: la columna, sin su espíritu forjado en la lucha todavía y sin una clara conciencia ideológica, no acababa de consolidarse" ([1963]: 21) ${ }^{39}$.

En todos esos elementos cristalizaba la representación de la guerrilla como un colectivo en continuo autodisciplinamiento y mejoramiento, y el eje narrativo basado en el paso de una situación de ingenuidad ideológica y bélica (los 'bisoños) a una de cohesión colectiva y solidez revolucionaria. Es

\footnotetext{
38 Pasajes narraba varias muertes de guerrilleros en pleno proceso de transformación subjetiva, y Guevara no dudaba definir su proceso de disciplinamiento como inacabado: “después me enteré que Julio Zenón Acosta había quedado para siempre en lo alto de la loma. El guajiro inculto, el guajiro analfabeto que había sabido comprender las tareas enormes que tendría la revolución después del triunfo y que se estaba preparando desde las primeras letras para ello, no podría acabar su labor" ([1963]: 28).

39 Esa autodisciplina del grupo guerrillero se complementaba, además, con una gran altura moral con respecto al enemigo: "Siempre contrastaba nuestra actitud con los heridos y la del ejército, que no solo asesinaba a nuestros heridos sino que abandonaba a los suyos. Esta diferencia fue haciendo su efecto con el tiempo y constituyó uno de los factores de triunfo. Allí, con mucho dolor para mí, que sentía como médico la necesidad de mantener reservas para nuestras tropas, ordenó Fidel que se entregaran a los prisioneros todas las medicinas disponibles para el cuidado de los soldados heridos, y así lo hicimos" ([1963]: 16).
} 
Jaume Peris Blanes. Relatos para una revolución potencial...

decir, una representación propicia a la emulación, y en la que el grupo guerrillero encarnaba la evolución social que haría posible el surgimiento de una nueva sociedad revolucionaria.

Sin embargo, Guevara se cuidaba mucho de construir una imagen idealizada y sin fisuras del grupo guerrillero y de su evolución revolucionaria. Por el contrario, en la narración de su progresivo disciplinamiento desempeñaban un rol crucial los errores de diferente naturaleza, algunos de ellos banales -aunque de importancia vital en las anécdotas en que se integraban- pero directamente autoatribuidos por Guevara, que asumía la responsabilidad en sus escritos como una forma de reconocer las contradicciones del proceso de construcción del sujeto revolucionario:

Hice un intento de repetir algo que había leído en algunas publicaciones semicientíficas o en alguna novela en que se explicaba que el agua dulce mezclada con un tercio de agua de mar da un agua potable muy buena y aumenta la cantidad de líquido; hicimos así con lo que quedaba de una cantimplora y el resultado fue lamentable; un brebaje salobre que me valió la crítica de todos los compañeros ([1963]: 9). ${ }^{40}$

Sin duda la consignación de esos errores y malas prácticas en la lucha guerrillera constituían la contracara del proceso emulativo que los Pasajes deseaban desencadenar: el texto ofrecía también, como parte de su pedagogía revolucionaria, las dificultades que el grupo guerrillero había tenido que enfrentar. Por ello, muchos de esos errores eran acompañados por un párrafo a modo de enseñanza derivada de ellos $^{41}$, o en algunos casos, de una admonición de Fidel o del propio Guevara en la que cristalizaba el sentido de ese error en el proceso de construcción del grupo revolucionario ${ }^{42}$.

En algunos momentos, sin embargo, la naturaleza de los desaciertos cometidos era de tal calibre que habían llegado a poner en riesgo todo el proceso revolucionario. Es el caso, por ejemplo, del pasaje dedicado al traidor Eutimio, a quien se le había asignado la misión de asesinar a Fidel y que consiguiera, gracias a una estratagema, dormir junto a Castro para compartir con él la escasez de mantas: "toda la

\footnotetext{
40 En la misma línea: "Establecí cuál era la Estrella Polar, según mis conocimientos en la materia, y durante un par de días fuimos caminando guiándonos por ella hacia el Este y llegar a la Sierra Maestra. (Mucho tiempo después me enteraría que la estrella que nos permitió guiarnos hacia el Este no era la Polar y que simplemente por casualidad, habíamos ido llevando aproximadamente este rumbo)" ([1963]: 8)

${ }^{41}$ Por ejemplo, en la escena en que Guevara narraba su desorientación y pérdida en la Sierra: "al encontrarme perdido, la mañana siguiente de la noche en que ocurriera, tomé la brújula y guiándome por ella seguí un día y medio hasta darme cuenta de que cada vez estaba más perdido, me acerqué a una casa campesina y allí me encaminaron hasta el campamento rebelde. Después nosotros nos percatamos de que en lugares tan escabrosos como la Sierra Maestra, la brújula solamente puede servir de orientación general, nunca para marcar rumbos definidos" ([1963]: 48).

42 "Nuestra pequeña tropa se presentaba sin uniforme y sin armamentos, pues las dos pistolas era todo lo que habíamos logrado salvar del desastre y la reconvención de Fidel fue muy violenta. Durante toda la campaña, y aún hoy, recordamos su admonición: "No han pagado la falta que cometieron, porque el dejar los fusiles en estas circunstancias se paga con la vida; la única esperanza de sobrevivir que tenían en caso de que el ejército topara con ustedes eran sus armas. Dejarlas fue un crimen y una estupidez" ([1963]: 12).
} 
Jaume Peris Blanes. Relatos para una revolución potencial...

noche, una buena parte de la Revolución de Cuba estuvo pendiente de los vericuetos mentales, de las sumas y restas de valor y miedo, de terror y, tal vez, de escrúpulos de conciencia, de ambiciones y de poder y de dinero, de un traidor" ([1963]: 27). Del mismo modo, en la crónica 'Pino del agua' Guevara narraba su error ante el prisionero Baró, que le había convencido para dejarlo en libertad con un relato patético sobre la salud de su madre para reincorporarse más tarde al ejército batistiano e identificar a los campesinos que colaboraban con la guerrilla. La conclusión de Guevara ante las consecuencias de su equivocación resultaban, sin duda, devastadoras: “innúmeras son las víctimas que costó mi error al pueblo de Cuba" ([1963]: 91).

Esas escenas funcionaban, dentro del relato ejemplarizante de Guevara, como una suerte de ejemplo negativo, que identificaba los espacios de sombra en el relato luminoso de una conciencia colectiva en transformación y disciplinamiento. Como se verá más adelante, en los relatos posteriores en torno a sus experiencias revolucionarias en el Congo y Bolivia esa negatividad narrativa dejaría de ser la excepción y se convertiría en regla.

\section{Un hiato entre la experiencia y su escritura}

Había en las crónicas de Pasajes de la guerra revolucionaria una serie de incisos, intermitentes pero recurrentes, en los que Guevara aludía a un desajuste esencial entre la experiencia vivida y su representación posible en el discurso, relacionado con la diferente naturaleza de ambos ámbitos : "todo esto se ha contado en pocos minutos, pero duró aproximadamente dos horas y 45 minutos desde el primer disparo hasta que logramos tomar el cuartel” ([1963]: 59). No se trataba, aquí, de la constatación de una falta de veracidad o una desconfianza ante la enunciación testimonial, sino de la consignación de un diferencia esencial entre el orden de la experiencia y el orden de la escritura, que dificultaba trasladar al lector, a través de ella, la forma en que los guerrilleros habían experimentado los episodios de la lucha.

En no pocos momentos ese desajuste obedecería a una clave subjetiva y su proceso de transformación que implicaba, como se ha dicho, situaciones de confusión y desorientación difícilmente representables de forma explícita. En ese contexto discursivo, el carácter caótico y violento de la lucha dificultaba su reconstrucción posterior, ya que el guerrillero no estaba, en el momento de la batalla, atento al detalle y a la observación, sino únicamente a su supervivencia. De ese modo, la confusión y violencia del combate se traducía en la imposibilidad de representar con precisión los acontecimientos ("no sé en qué momento ni cómo sucedieron las cosas: los recuerdos son ya borrosos", [1963]: 6) y en la incertidumbre con respecto a la fiabilidad de lo narrado: "se levantaban columnas de humo y fuego; aunque esto no lo puedo asegurar, porque pensaba más en la amargura de la derrota y en la inminencia de mi muerte, que en los acontecimientos de la lucha" ([1963]: 7). 
Jaume Peris Blanes. Relatos para una revolución potencial...

Con respecto a esa imprecisión del discurso testimonial, el propio Guevara incluía un elemento más a tener en cuenta: la vanidad o los intereses del narrador ${ }^{43}$. De ese modo, el propio texto señalaba sus límites como representación directa de la realidad de la que trataba de dar cuenta, y parecía socavar su autoridad para fijar una versión totalmente fiable de lo ocurrido. Por una parte, Guevara parecía cuestionar la propia validez del discurso testimonial, reconociendo sus limitaciones y la 'tendencia a la fantasía', que le llevaba a cuestionar el relato de sus compañeros. Pero por otra, al hacerlo multiplicaba quizás el efecto de verdad que se derivaba de él, haciendo de esa autoconsciencia un valor probatorio de mayor fiabilidad que la seguridad ingenua en las bondades del narrador testimonial.

Guevara aludía, en diferentes momentos, a otro gran conflicto de escritura, relacionado con el punto de vista y la posición desde la que narrar los acontecimientos de la lucha. Desde su prólogo, Pasajes de la guerra revolucionaria se había preocupado por integrar su relato en un conjunto de narraciones testimoniales más amplio que, complementándose, llegaran a construir una mirada global sobre la lucha insurrecional. Establecía de ese modo una tensión fundamental entre el carácter colectivo de los acontecimientos narrados, cuyo sujeto de acción era el grupo guerrillero, y la enunciación individual, ligada a un sujeto reconocido públicamente como heroico y con intereses muy determinados en el proceso político abierto tras el triunfo de la revolución, que fue el contexto en el que Pasajes fue publicado.

¿Cómo narrar, pues, un acontecimiento con una dimensión colectiva insoslayable desde la percepción de un único individuo implicado? En algunos momentos del texto, Guevara trataba de superar esa contradicción complementando su saber como testigo con el de otros compañeros que hubieran participado en las mismas acciones:"Después de este combate, uno de los más sangrientos que hayamos sostenido, fuimos atando cabos y se puede dar una imagen más general y no desde el enfoque que hice hasta aquí relatando mi participación personal” ([1963]: 60). Así, el relato pasaba a nutrirse del saber contenido en otras voces y, en determinados momentos, a aventurar la posibilidad de una enunciación colectiva. A esa idea apuntaba en el siguiente fragmento, en el que la referencia a la participación personal aparecía como excepcional con respecto a una lógica de representación que ponía en el centro a la experiencia colectiva.

Estas notas tratan de dar una idea de lo que fue para el total de los combatientes la primera parte de nuestra lucha revolucionaria; si en este pasaje de los recuerdos tengo que referirme, más que en el resto, a mi participación personal, es porque tiene conexión con los siguientes episodios y no era posible desligarlos sin que se perdiera unidad en el relato ([1963]: 33).

\footnotetext{
43 “Todavía de madrugada continuaban narrándose las incidencias del combate (...). Por curiosidad estadística tomé nota de todos los enemigos muertos por los narradores durante el curso del combate y resultaban más que el grupo completo que nos había opuesto; la fantasía de cada uno había adornado sus hazañas. Con ésta y otras experiencias similares, aprendimos claramente que los datos deben ser avalados por varias personas" ([1963]: 62).
} 
Jaume Peris Blanes. Relatos para una revolución potencial...

En buena medida, la crónicas testimoniales que conformaron Pasajes de la guerra revolucionaria eran el espacio de esta tensión siempre irresuelta y no exenta de contradicciones. Si, efectivamente, había crónicas enteras destinadas al análisis de la evolución colectiva sin apenas presencia de rasgos personales ("Un año de lucha armada", [1963]: 118-138), en otras el enfoque discursivo estaba tan pegado a las vivencias subjetivas del propio Guevara que podrían considerarse, en algunos momentos como una exploración fenomenológica del combate $^{44}$ a través de las vivencias de su figura más emblemática.

Del mismo modo, algunas de las escenas relatadas en las crónicas testimoniales derivaban en reflexiones que, en cierta medida, suponían una legitimación explícita de las elecciones políticas tomadas por el gobierno revolucionario y por el propio Guevara en los años posteriores a la lucha guerrillera. Por ejemplo, al referir un gesto de honestidad política de Urrutia en el periodo revolucionario, señalaba que "tuvo las consecuencias de entronizar a un mal presidente incapaz de comprender el proceso político siguiente, incapaz de asimilar la profundidad de una revolución que no estaba hecha para su mentalidad retrógrada" ([1963]: 52). De ese modo, la narración testimonial de un suceso de 1957 servía para legitimar actuaciones políticas que tendrían lugar en 1959, ya en pleno gobierno revolucionario.

En una lógica similar, algunas de las escenas concretas vividas en la Sierra eran descritas desde el horizonte de las futuras políticas revolucionarias, sirviéndoles, por tanto, de carta de legitimidad. En una crónica vibrante, Guevara narraba cómo había ejercido de médico con los pobladores de la Sierra Maestra. A pesar de sus esfuerzos, una niña decía: "Mamá, este doctor a todas les dice lo mismo".

Y era una gran verdad (...) todas tenían el mismo cuadro clínico y contaban con la misma historia desgarradora sin saberlo. (...) Allí, en aquellos trabajos empezaba a hacerse carne en nosotros la conciencia de un cambio definitivo en la vida del pueblo. La idea de la reforma agraria se hizo nítida y la comunión con el pueblo dejó de ser teoría para convertirse en parte definitiva de nuestro ser. (...) ¡Nunca han sospechado aquellos sufridos pobladores de la Sierra Maestra el papel que desempeñaron como forjadores de nuestra ideología revolucionaria! ([1963]: 49).

De ese modo, Guevara establecía una vinculación explícita entre el trabajo realizado por el grupo guerrillero y él mismo en la Sierra y la concepción política de la reforma agraria, que iba a convertirse en una de las grandes apuestas políticas del gobierno revolucionario. Como se desprende del texto, Guevara situaba a los pobladores de la Sierra -campesinos, pobres, miembros de una clase históricamente

\footnotetext{
${ }^{44}$ No de otra forma puede entenderse la famosa escena de 'Alegría del Pío' en que Guevara se tumba a esperar a la muerte: "Quedé tendido; disparé un tiro hacia el monte siguiendo el mismo oscuro impulso del herido. Inmediatamente, me puse a pensar en la mejor manera de morir en ese minuto en que parecía todo perdido. Recordé un viejo cuento de Jack London, donde el protagonista, apoyado en un tronco de árbol se dispone a acabar con dignidad su vida, al saberse condenado a muerte por congelación, en las zonas heladas de Alaska. Es la única imagen que recuerdo. Alguien, de rodillas, gritaba que había que rendirse y se oyó atrás una voz, que después supe pertenecía a Camilo Cienfuegos, gritando "Aquí no se rinde nadie”... y una palabrota después" ([1963]: 7).
} 
Jaume Peris Blanes. Relatos para una revolución potencial...

excluida de cualquier posibilidad de agencia política- en un lugar germinal con respecto al diseño y la construcción de las políticas revolucionarias. Y además, se servía de la 'experiencia vivida’ para legitimar su apuesta política.

Por todo ello, sus crónicas de la guerra revolucionaria cubana constituían, sin duda, un documento de primer orden para conocer y fijar los acontecimientos vividos en ella, pero a la vez esa experiencia era representada desde los intereses políticos y estratégicos de uno de los actores fundamentales del proceso del que se trataba de dar cuenta e, inevitablemente, aparecían contaminados por ellos. Al igual que Guevara había detectado en la narración que sus soldados hacían del combate la influencia de sus intereses y vanidades, los Pasajes no solo mostraban un idea definida y situada de cómo había transcurrido la guerra de guerrillas, sino también una concepción muy clara de cómo su puesta en relato podía ser utilizada para servir a intereses revolucionarios.

La publicación de Pasajes, pues, no tenía como único objetivo construir una memoria fidedigna de la lucha insurreccional, sino que suponía una acción política estratégica de calado dentro del proceso revolucionario. Una acción estratégica, como ya se ha dicho, con un doble horizonte. En el interior del proceso cubano permitía, al mismo tiempo, legitimar afectivamente políticas de gran impacto público, apuntalar el liderazgo de Fidel Castro en el proceso político y, sobre todo, consolidar una teoría implícita de la revolución como transformación de la conciencia y la subjetividad. ${ }^{45}$ En el ámbito internacional, apuntaba a generar el marco emocional y narrativo para que el carisma del Che se tradujera en prácticas de emulación que derivaran en una extensión e internacionalización de las luchas insurreccionales en el resto de América Latina y el mundo.

En cualquier lugar que nos sorprenda la muerte, bienvenida sea, siempre que ese, nuestro grito de guerra, haya llegado a un oído receptivo, y otra mano se tienda para empuñar nuestras armas, y otros hombres se apresten a entonar los cantos luctuosos con tableteo de ametralladoras y nuevos gritos de violencia y de victoria (Guevara, [1967]: 598).

\section{El modelo negativo}

Pasajes de la guerra revolucionaria: Congo, que narra la experiencia de Guevara y un grupo de guerrilleros cubanos en el país africano en 1965, no llegó a publicarse en vida de su autor y no fue publicado hasta más de treinta años después, en $1999 .{ }^{46}$ Escrito con el mismo método que las crónicas

\footnotetext{
45 Una teoría que, como se ha visto, era central para la aceptación de sus tesis sobre el trabajo voluntario y los incentivos morales como factores que podrían facilitar la transición al verdadero socialismo, algo que estaba en el corazón de la teoría política guevariana.

${ }^{46}$ El propio Guevara advertía de la necesaria demora en la publicación, con el fin de mantener en secreto la intervención cubana en el Congo: "Estas notas serán publicadas transcurrido bastante tiempo desde su dictado y, tal vez, el autor no pueda ya hacerse responsable de lo que aquí está dicho" (17).
} 
Jaume Peris Blanes. Relatos para una revolución potencial...

de la guerrilla cubana, a partir de diarios tomados en la guerra, el libro sobre el Congo fue pensado con un propósito totalmente diferente, aunque complementario, del de su predecesor. Si las crónicas de la guerrilla cubana tenían como objetivo fundamental servir como ejemplo e inspiración para las nuevas generaciones de guerrilleros, en perfecta complementariedad con el manual La guerra de guerrillas, el libro sobre el Congo proponía la experiencia vivida allí como un modelo negativo para esas nuevas generaciones. Si lo vivido en la lucha cubana había servido para elaborar una teoría de la revolución basada en la transformación cualitativa del grupo guerrillero, la experiencia del Congo podía servir para teorizar sobre las condiciones en las que esa transformación no tendría lugar y, por tanto, para falsar el estatuto de universalidad que tanto en La guerra de guerrillas como en Pasajes... se otorgaba a las estrategias revolucionarias desarrolladas en la lucha insurreccional cubana.

Esta es la historia de un fracaso. Desciende al detalle anecdótico, como corresponde a episodios de la guerra, pero está matizada de observaciones y de espíritu crítico ya que estimo que, si alguna importancia pudiera tener el relato, es la de permitir extraer experiencias que sirvan para otros movimientos revolucionarios. La victoria es una gran fuente de experiencias positivas pero también lo es la derrota, máxime considerando las circunstancias extraordinarias que rodean el episodio (1999: 17).

Pasajes... había puesto en relato la evolución subjetiva y disciplinaria de los integrantes del grupo guerrillero; el texto sobre el Congo partía de la constatación, desgarradora, de que esa evolución no había llegado a tener lugar, y que por tanto no había narratividad posible más que la espera de algo que nunca llegaba a tener lugar. En ese sentido, Pasajes de la guerra revolucionaria: Congo puede considerarse el Esperando a Godot de la crónica testimonial: el relato sobre las expectativas de un acontecimiento - la transformación revolucionaria del grupo guerrillero- que nunca llegaba a tener lugar. No se trataba, pues, de la crónica de un fracaso militar ni de un análisis político o social de la situación histórica del Congo, sino de la narración del fracaso de la moral combativa de un grupo guerrillero muy similar, en su composición, al que había protagonizado las gestas de la Sierra Maestra, y capitaneado por el mismo Guevara.

Lo más interesante aquí no es la historia de la descomposición de la Revolución congolesa, cuyas causas y características son demasiado profundas para abarcarlas todas desde mi punto de observación, sino el proceso de descomposición de nuestra moral combativa, ya que la experiencia inaugurada por nosotros no debe desperdiciarse, y la iniciativa del Ejército Proletario Internacional no debe morir frente al primer fracaso. Es preciso analizar a fondo los problemas que plantean y resolverlos (1999: 17).

Se trataba de una idea ya aparecida en las crónicas cubanas: los errores y fracasos podían ser tan educativos, en el interior de una pedagogía revolucionaria, como las grandes victorias. Sin embargo, en los Pasajes sobre el Congo la crónica del error no era ya la excepción que puntuaba el relato de una 
Jaume Peris Blanes. Relatos para una revolución potencial...

exitosa transformación colectiva, sino el motor mismo de la narración y su razón de ser. Ya no se trataba de un ejemplo digno de emulación, sino de un modelo de acción negativo que había de ser estudiado para no volverse a repetir.

En la construcción de ese modelo negativo se imbricaban múltiples factores, entre ellos el choque cultural entre los guerrilleros cubanos y los congoleses, con experiencias del tiempo y visiones del mundo sustantivamente diferentes, que en múltiples situaciones dificultaban la coordinación y el entendimiento militar. En algunas ocasiones, la descripción que Guevara hacía de la inoperancia, ingenuidad y falta de preparación del grupo guerrillero congolés resultaba francamente desesperante, como en el pasaje en el que el coronel Lambert le explicaba cómo para ellos los aviones no tenían ninguna importancia porque poseían la dawa, medicamento que les hacía invulnerables a las balas ${ }^{47}$. En cualquier caso, narrativamente los Pasajes del Congo presentaban una dirección narrativa casi opuesta a la de los Pasajes cubanos: el relato de la transformación colectiva era hacia el caos, la desorganización y la indisciplina, y Guevara buscaba las imágenes capaces de cifrar metafóricamente ese estado: “con el correr de los días se hacía más clara la imagen del caos organizativo; participé personalmente en el reparto de las medicinas soviéticas y aquello parecía un mercado gitano" (1999: 26).

\section{La escritura de la disolución}

Las imágenes de caos, desorientación y fracaso que nutrían las páginas de Pasajes de la guerra revolucionaria: Congo palidecen, sin embargo, frente a la escritura desolada y progresivamente despojada de esperanza del Diario de Bolivia. Se trata, como es lógico, de un texto con una factura totalmente diferente a la de los anteriores, que no fue reescrito para su publicación por el autor y que, por tanto, no es comparable en su grado de elaboración y organización con ellos ${ }^{48}$. En ese sentido, el Diario de Bolivia no puede leerse, como el resto de los textos analizados, como parte de su proyecto político, sino únicamente como un material de base que recoge aquellos elementos que el propio Guevara entendía que eran significativos de la experiencia guerrillera en Bolivia. Aún así, se trata del

\footnotetext{
47 “-A mí me han dado varias veces y las balas caen sin fuerza al suelo.

Lo explicó entre sonrisas y me sentí obligado a festejar el chiste en que veía una forma de demostrar la poca importancia que se le concedía al armamento enemigo. A poco me di cuenta de que la cosa iba en serio y que el protector mágico era una de las grandes armas de triunfo del ejército congolés. Esta dawa hizo bastante daño para la preparación militar. El principio es el siguiente: un líquido donde están disueltos jugos de hierbas y otras materias mágicas se echa sobre el combatiente al que se le hacen algunos signos cabalísticos y, casi siempre, una mancha con carbón en la frente; está ahora protegido contra toda clase de armas del enemigo" (1999: 23).

${ }^{48}$ Sería comparable, en cualquier caso, con el Diario de un combatiente de Guevara o con las notas originales que sirvieron de material de base para sus otros libros.
} 
Jaume Peris Blanes. Relatos para una revolución potencial...

texto más leído de su autor y, probablemente, del que ha recibido usos más variados y heterogéneos, muchos de ellos contrarios a la función que Guevara había pensado para sus textos revolucionarios. En cualquier caso, puede establecerse una continuidad importante entre los Pasajes... sobre el Congo y la dinámica de la que dan cuenta los diarios bolivianos: la experiencia del fracaso en la construcción del núcleo guerrillero, de la progresiva desestructuración moral y política del grupo de la que daba cuenta en sus escritos sobre el Congo llegaba a límites extremos en su escritura boliviana.

Ya desde los primeros días Guevara consignaba la velocidad de deterioro del grupo, aunque al principio esa constatación iba acompañada todavía por una esperanza de mejora: "Esto se deteriora rápidamente; hay que ver si nos permiten traer aunque sea a nuestros hombres. Con ellos estaré tranquilo" (DB, 10 noviembre: 458). Sin embargo, y a pesar de que el Diario presenta una extraordinaria obstinación en la creencia de la inevitabilidad del triunfo guerrillero, esa esperanza iría desapareciendo progresivamente, viéndose desplazada por múltiples urgencias y exigencias que no habían sido previstas.

Una de las características principales del Diario de Bolivia, y lo que lo diferenciaba de sus otros textos, es que la evolución negativa del grupo guerrillero se hallaba acompañada de una transformación paralela en la escritura. En ese sentido, el Diario literalizaba de un modo mucho más concluyente que sus textos anteriores la idea nuclear en su teoría de la escritura de que el sujeto que escribía en ella se transformaba radicalmente a través de la vivencia de los episodios narrados: “yo, no soy yo'; por lo menos no soy el mismo yo interior” escribía en sus crónicas de viaje (Guevara, 1992: 17-18). Ese yo que se transforma era especialmente visible en el Diario de Bolivia, por lo que no solo se leía en él la desestructuración del grupo guerrillero sino también, y sobre todo, la disolución progresiva de una voz, la del propio Guevara, capaz de dar sentido y valor a esa experiencia histórica.

Efectivamente, en el Diario de Bolivia era legible una voz que iba abandonando progresivamente, y a medida que se endurecían sus condiciones materiales de existencia, su capacidad de analizar la realidad circundante desde una perspectiva compleja y políticamente productiva. De hecho, buena parte de las páginas del Diario constituían un análisis de la situación político-militar de la guerrilla, pero el deterioro del grupo, la presencia cada vez más inasumible de un cuerpo doloroso y el deterioro radical de las condiciones médicas y de alimentación se traducían en una transformación progresiva de la voz, cada vez más centrada en las urgencias de un cuerpo exhausto y descontrolado.

De hecho, la presencia de un cuerpo en transformación que Guevara tenía dificultad de controlar aparecía, aunque con un diferente sentido, desde las primeras semanas. Dado que el viaje a Bolivia lo había hecho bajo una identidad falsa y con una apariencia prestada, una de sus preocupaciones consistía en recuperar su apariencia física habitual: "Mi pelo está creciendo, aunque muy ralo y las canas se 
Jaume Peris Blanes. Relatos para una revolución potencial...

vuelven más rubias y comienzan a desaparecer. Dentro de un par de meses volveré a ser yo" (DB, 12 noviembre, 459). El fragmento es significativo por lo que tiene de premonitorio: el cuerpo de Guevara como espacio de identidad y como lugar en el que se iba a jugar, en buena medida, el destino de la guerrilla boliviana.

Desde el principio del diario, Guevara ponía el foco en aquellos procesos y dinámicas que impedían el desarrollo de la disciplina guerrillera de la manera en que había tenido lugar en Cuba. En el centro de esa problemática, la dificultad para establecer una convivencia basada en la solidaridad y el compañerismo: "Los incidentes desagradables entre compañeros están estropeando el trabajo" (DB 6 enero, 481); "por la noche me informó que Polo se había tomado su lata de leche y Eusebio la de leche y las sardinas, por ahora, como sanción, no comerán cuando toquen esas cosas. Mal síntoma” (DB, 1 marzo, 505). Al constatar los efectos de ese déficit organizativo y de solidaridad interna, Guevara introducía al factor físico como un elemento central, y consignaba su propio deterioro corporal casi como una extensión de las dinámicas negativas del grupo: "el ánimo de la gente está bajo y el físico se deteriora día a día; yo tengo comienzo de edemas en las piernas" (DB 4 marzo, 506). En ese contexto, más que las dificultades para llevar a cabo la estrategia militar, las causas que Guevara daba a la creciente ansiedad y descontento del grupo guerrillero se hallaban relacionadas con las condiciones materiales, médicas y de alimentación del grupo: "cuatro meses. La gente está cada vez más desanimada, viendo llegar el fin de las provisiones, pero no del camino" (DB ,7 marzo, 507).

A medida que avanzaba el diario proliferaban en él las imágenes del caos y la desorganización: "Un clima de derrota imperaba (...). Todo da la impresión de un caos terrible; no saben qué hacer” (DB, 20 marzo, 513). Frente a la progresión en la disciplina colectiva que caracterizaba a la narrativa de Pasajes..., en el Diario de Bolivia se consignaba recurrentemente la dificultad, cada vez más palmaria, de transformar al grupo desorganizado en un colectivo capaz de combatir: la narrativa de la transformación subjetiva y colectiva aparecía en él como un modelo aspiracional, pero que era recurrentemente desmentido por la realidad:

El balance de la acción es negativo; indisciplina e imprevisión por un lado, la pérdida (aunque espero transitoria) de un hombre, por otro; mercancía que pagamos y no llevamos y, por último, la pérdida de un paquete de dólares que se me cayó de la bolsa de Pombo, son los resultados de la acción. Sin contar con que nos sorprendió y puso en retirada un grupo que necesariamente debía ser pequeño. Falta mucho para hacer de esto una fuerza combatiente (DB, 22 abril, 536).

Esa incapacidad para desencadenar la transformación subjetiva y grupal producía efectos en múltiples niveles, que Guevara no dudaba en resaltar: experiencias de desorientación y confusión 
Jaume Peris Blanes. Relatos para una revolución potencial...

geográfica ${ }^{49}$, imposibilidad de mantener una higiene mínima ${ }^{50}$ y episodios crecientes de indisciplina y deserción. Pero sobre todos ellos sobrevolaba la presencia de un cuerpo cada vez más enfermo, doloroso e incontrolable ${ }^{51}$, cuyas exigencias fisiológicas iban desplazando en el diario a las consideraciones políticas y estratégicas ${ }^{52}$.

Día de eruptos, pedos, vómitos y diarreas; un verdadero concierto de órgano. Permanecimos en una inmovilidad absoluta tratando de asimilar el puerco. Tenemos dos latas de agua. Yo estuve muy mal hasta que vomité y me compuse (DB 13 mayo, 548).

Al comenzar la caminata, se me inició un cólico fortísimo con vómitos y diarrea. Me lo cortaron con demerol y perdí la noción de todo mientras me llevaban en hamaca; cuando desperté estaba muy aliviado pero cagado como un niño de pecho. (...) Se recibió el mensaje no 36 , de donde se desprende el total aislamiento en el que estamos" ( 16 de mayo, 549-550).

El asma me está amenazando seriamente y hay muy poca reserva de medicamentos (DB junio 23, $567)$.

El asma ya había aparecido como un obstáculo importante en Pasajes ${ }^{53}$, pero en el Diario de Bolivia iba a adquirir una centralidad llamativamente sintomática: la presencia de un cuerpo incontrolable no solo dificultaba la acción colectiva sino que, además, anulaba la capacidad analítica del sujeto de enunciación, que progresivamente iba replegándose sobre su propia materialidad fisiológica. En las entradas centrales del diario, cuando el deterioro físico ya era notable pero todavía no definitivo, se hacía recurrente una estructura narrativa en la que, tras la descripción de las acciones de combate, Guevara consignaba también su estado físico, en una estructura enunciativa que les daba una paridad jerárquica: el dolor corporal, pues, se situaba a un mismo nivel que el desarrollo de la lucha guerrillera.

Luego de descansar un rato, 8 soldaditos emprendieron la marcha hacia la emboscada. Sólo cayeron en ella 4, pues el resto venía un poco reposado; hay 3 muertos seguros y el cuarto probable, pero de todas maneras herido. Nos retiramos sin quitarle las armas y equipo por lo

\footnotetext{
49 "Día de lento avance y confusión sobre la situación geográfica" (DB 2 mayo, 543); "Estamos, pues, en el arroyo del Congri, que no figura en el mapa, muy al norte de donde pensábamos. Esto plantea varias interrogantes: ¿dónde está el Iquiri?; ¿no sería aquél donde Benigno y Aniceto fueron sorprendidos?; ¿los agresores, no serían gente de Joaquín?” (DB 5 mayo, 544).

50 "Se me olvidaba recalcar un hecho: hoy, después de seis meses, me bañé. Constituye un récord que ya varios están alcanzando" (DB, 10 septiembre, 612).

${ }^{51}$ El deterioro del cuerpo era paralelo al deterioro de la acción guerrillera: "Llegamos al rancho denominado Loma Larga, yo con un ataque al hígado, vomitando, y la gente muy agotada por las caminatas que no rinden nada. (...) el único campesino que quedó en su casa: Sóstenos Vargas; el resto huye al vernos” (DB, 24 septiembre 620).

52 Junto a las jornadas de fracaso personal (“Día negro para mí”. [DB 26 junio 568]) Guevara tematizaba, además, su propio envejecimiento, que lo hacía crecientemente inadecuado para la guerrilla: "He llegado a los 39 y se acerca inexorablemente una edad que da que pensar sobre mi futuro guerrillero; por ahora estoy “entero”” ( DB 14 junio, 562).

53 “El asma era tan fuerte que no me dejaba avanzar bien” ([1963]: 34).
} 
Jaume Peris Blanes. Relatos para una revolución potencial...

difícil que se hacía el rescate y salimos arroyo abajo. Luego de la confluencia con otro cañoncito se hizo una nueva emboscada, los caballos avanzaron hasta donde llega el camino.

El asma me trató duro y se van acabando los míseros calmantes (DB, 27 julio, 584).

Somos 22, entre ellos dos heridos, Pacho y Pombo, y yo, con el asma a todo vapor (DB, 31 julio 588)

Lo del camino resultó un fiasco; Miguel y Urbano tardaron 57 minutos en regresar hoy; se avanza muy lentamente. No hay noticias. Pacho se recupera bien, yo, en cambio estoy mal; el día y la noche estuvieron duros para mí y no se vislumbra salida a corto plazo. Probé la inyección endovenosa de novocaína sin resultado" (DB, 3 agosto, 589).

Hoy se cumplen 9 meses exactos de la constitución de la guerrilla con nuestra llegada. De los 6 primeros, dos están muertos, uno desaparecido y dos heridos; yo con asma que no sé cómo cortarla (DB, 7 agosto, 591).

Salieron por la mañana los 8 exploradores. Los macheteros, Miguel, Urbano y León se alejaron 50 minutos más del campamento. Me abrieron un ántrax en el talón, lo que me permite apoyar el pie, pero todavía muy dolorido y con fiebre (DB, 9 agosto, 592).

Esa creciente presencia de una corporalidad insoportable derivaba en algunos episodios de pérdida de control subjetivo ${ }^{54}$, en el que el propio Guevara llegaba a caracterizarse como una 'piltrafa humana':

Caminamos algo así como una hora efectiva, que para mí fueron dos por el cansancio de la yegüita; en una de esas le metí un cuchillazo en el cuello abriéndole una buena herida (...). Por la noche reuní a todo el mundo haciéndole la siguiente descarga: Estamos en una situación difícil; el Pacho se recupera pero yo soy una piltrafa humana y el episodio de la yegüita prueba que en algunos momentos he llegado a perder el control (DB 8 agosto, 591-592).

Guevara ponía el énfasis en su propia pérdida de control como síntoma definitivo de la dinámica de caos y desorganización del núcleo guerrillero, en el que empezaban a proliferar los estallidos psicológicos $^{55}$. En las semanas siguientes, el análisis político y militar que había caracterizado a las entradas del diario de los primeros meses sería sustituido progresivamente por la evaluación de las

\footnotetext{
54 "Mientras observaba la caza vi como le picaban las balas cerca, por efecto de tiros de nuestro lado, salí corriendo y me encontré con que Eustaquio les estaba tirando, pues Antonio no le había avisado de nada. Tenía una furia tan grande que perdí el control y maltraté a Antonio" (DB, 26 agosto, 600).

55 "Eustaquio viene a avisar que avanza gente por el arroyo; llamó a las armas y se movilizó todo el mundo; Antonio los ha visto y, cuando le pregunto cuántos son, me contesta con la mano que cinco. A fin de cuentas, resultó una alucinación, peligrosa para la moral de la tropa pues enseguida se comenzó a hablar de psicosis” (DB, 12 septiembre 613).
} 
Jaume Peris Blanes. Relatos para una revolución potencial...

condiciones inmediatas de supervivencia ${ }^{56}$, la alimentación ${ }^{57}$, la ausencia de materiales básicos ${ }^{58}$, el estado de las heridas y las condiciones generales del cuerpo, tanto del propio Guevara como de los demás miembros del grupo guerrillero ${ }^{59}$.

Entre el principio y el final del diario, pues, mediaba un proceso de descomposición subjetiva que, de algún modo, metonimizaba la desarticulación del grupo guerrillero y la imposibilidad de transformarlo en un colectivo capaz de desencadenar, de acuerdo a la teoría del foco, las condiciones necesarias para una lucha insurreccional global. Ese proceso se concretaba en la transformación de la escritura que tomaba cuerpo en los diarios: de un sujeto fuertemente analítico, atento a los procesos de transformación individual y colectiva, a un sujeto desestructurado, herido por el dolor físico e incapaz de articular una mirada política sobre los acontecimientos narrados. El diario daba cuenta del fracaso del proyecto insurreccional, por tanto, no solo narrando sus vicisitudes sino a través de la propia disolución de esa voz fuerte, propia de un líder revolucionario, que podía leerse en sus primeras páginas y que se hallaba radicalmente fracturada en su tramo final.

Así pues, Diario de Bolivia puede considerarse como un cierre involuntario pero radical del ciclo narrativo abierto por Guevara en las crónicas de Pasajes de la guerra revolucionaria. La voz que en ellas se construyera, fuertemente documental pero atenta a la dimensión política y transformadora de los acontecimientos, llegaba a su fin en la progresiva desestructuración subjetiva que era legible en la escritura del diario. Si bien, como es lógico, el diario no podía representar el momento crucial de la muerte de Guevara, que iba a convertirlo definitivamente en mito intergeneracional y en icono mundial, sí permitía leer la disolución de esa subjetividad en transformación revolucionaria y capaz de consignar las energías transformadoras que atravesaban los acontecimientos narrados y que debían alimentar, según la teoría guevariana, el proceso revolucionario.

\footnotetext{
56 "Quedan 4 animales y todo parece indicar que habrá que sacrificar otro antes de llegar a la comida. Si todo ha marchado bien, Coco y Aniceto deben llegar aquí mañana. Arturo cazó dos pavas que me fueron adjudicadas en razón de que ya casi no queda maíz. El Chapao está dando pruebas crecientes de desequilibrio, Pacho mejora a buen ritmo y mi asma tiene tendencia a aumentar desde ayer, ahora tomo 3 tabletas al día. El pie está casi bien” (DB Agosto 13, 594).

57 “Al anochecer volvieron los macheteros con las trampas, un cóndor y un gato podrido, todo fue a parar adentro junto con el último pedazo de anta; quedan los frijoles y lo que se cace. El Camba está llegando al último extremo de su degradación moral; ya tiembla ante el solo anuncio de los guardias. El Médico sigue dolorido y administrándose tamonal; yo bastante bien pero con un hambre atroz" (DB 24 agosto, 599).

58 "Signo de los tiempos: se me acabó la tinta" (DB, 19 septiembre, 617).

${ }^{59}$ Las últimas semanas del diario inauguraban un nuevo registro que, en consonancia con el rumbo de los acontecimientos, aludía al carácter angustioso e insoportable de los días: "Día negro." (DB, Agosto 14, 594), “día pesaroso y bastante angustioso" (DB, 29 agosto, 602), "ya la situación se tornaba angustiosa; los macheteros sufrían desmayos, Miguel y Darío se tomaban los orines y otro tanto hacía el Chino, con resultados nefastos de diarrea y calambres. Urbano, Benigno y Julio bajaron a un cañón y encontraron agua" (DB, 30 agosto, 602).
} 


\section{Relatos constituyentes para las luchas futuras}

De acuerdo a todo lo que antecede, debemos pensar las crónicas testimoniales de Guevara y los textos escritos en plena dinámica insurreccional como extensiones, a veces exitosas y otras frustradas, del proyecto de revolución global que alentó la práctica política y militar de su autor. Es bien cierto que los escritos de Guevara, unidos al magnetismo de su figura pública, espolearon un tipo de producción cultural marcada por el documentalismo, la consignación de la experiencia vivida y la narración de episodios de lucha e insurrección: en ese sentido, constituyeron un referente fundamental para las nuevas producciones testimoniales que, a lo largo de los años setenta, iban a consolidarse como uno de los rumbos fundamentales de la cultura crítica latinoamericana. Sin embargo, la idea de lo testimonial que iba a cristalizar en muchas de esas nuevas textualidades se correspondía bien poco con el proyecto que alimentó las escrituras narrativas de Guevara. Es más, habitualmente ha opacado su verdadera naturaleza y la función que su autor diera a la enorme energía que destinó, en tiempos vertiginosos y marcados por la acción, a la escritura: generar relatos constituyentes capaces de alimentar, en una suerte de pedagogía narrativa, las luchas que estaban por venir.

En ese sentido, puede localizarse en los textos de Guevara una enseñanza fundamental, que debería llevarnos a reconsiderar la función posible de las producciones testimoniales y su rol en los proceso de transformación social. Por una parte, claro, consignación de los procesos históricos en su singularidad y contingencia, necesaria para la comprensión cabal de un pasado que no deja de producir efectos en nuestro presente. Pero por otra apertura a lo potencial, a lo que todavía no ha llegado pero pugna por emerger, a las luchas e insurrecciones futuras que necesitarán relatos constituyentes sobre los que sostenerse para echar a andar. 
Jaume Peris Blanes. Relatos para una revolución potencial...

\section{Bibliografía}

Anderson, Jon Lee (1997). Che Guevara. Una vida revolucionaria. Barcelona: Emecé.

Benedetti, Mario. "Sobre las relaciones entre el hombre de acción y el intelectual”. Ruedo Ibérico 16 (1968): 20-25.

Calveiro, Pilar (2005). Política y/o violencia. Una aproximación a la guerrilla de los años setenta. Buenos Aires: Norma.

Castro, Fidel. “Una introducción necesaria” en Guevara [1970]: 437-545.

Castro, Fidel. (1961). 'Palabras a los intelectuales'.

Castaneda, Jorge (1997). Che: la vida en rojo. Madrid: Alfaguara.

Cortés Rocca, Paola. "Biblioteca y revolución. Ernesto Guevara, fotografías de lectura”. Revista Laboratorio 11 (2014).

Díez, Juan Antonio. “De puño y letra. Algunas reflexiones en torno al Che, sus escritos y su época”. Nueva Sociedad 201 (2006): 33-44.

Fernández Retamar, Fernando. "La creación artística en la Cuba revolucionaria”. Siempre (8/8/1962).

Fernández Retamar, Roberto (1970). “Usted tenía razón, Tallet, somos hombres de transición”. A quien pueda interesar (poesía 1958-1970). México: Siglo XXI: 114-17.

Fernández Retamar, Roberto. "Sobre Pasajes de la guerra revolucionaria”. Casa de las Américas 206 (1997): 108-114.

Fornet, Jorge (2013). El 71. Anatomía de una crisis. La Habana: Letras Cubanas.

Franco, Jean (2003). Decadencia y caída de la ciudad letrada: la literatura latinoamericana durante la guerra fría. Debate Editorial.

García, Victoria. "De Che Guevara a Enrique Raab. Viajeros argentinos a la revolución cubana”. Castilla. Estudios de Literatura 6 (2015): 269-313

González Echeverría, Roberto. "Biografía de un cimarrón and the Novel of the Cuban Revolution”. Novel: a Forum on Fiction 13.3 (1980): 249-263.

Gilman, Claudia. (2003). Entre la pluma y el fusil. Debates y dilemas del escritor revolucionario en América Latina. Buenos Aires: Siglo XXI.

Gilman, Claudia. "Maneras de decir: el canto de la acción. El Che Guevara, polígrafo salvaje” El interpretador 36 .

Guevara, Ernesto [1959] (1970). "Qué es un guerrillero". Obras 1957-1967. Tomo I. La Habana: Casa 
Jaume Peris Blanes. Relatos para una revolución potencial...

de las Américas: 153-160.

Guevara, Ernesto [1960] (1970). "La guerra de guerrillas". Obras 1957-1967. Tomo I. La Habana: Casa de las Américas: 25-149.

Guevara, Ernesto [1960] (1970). “Carta a Ernesto Sábato”. Obras 1957-1967. Tomo II. La Habana: Casa de las Américas: 676-680.

Guevara, Ernesto [1962] “En homenaje a los premiados en la Emulación”. Obras 1957-1967. Tomo II. La Habana: Casa de las Américas: 136-153.

Guevara, Ernesto. [1964] (1970). "Una actitud nueva frente al trabajo”. Obras 1957-1967. Tomo II. La Habana: Casa de las Américas: 332-350.

Guevara, Ernesto [1964b] (1970). "Carta a León Felipe”. Obras 1957-1967. Tomo II. La Habana: Casa de las Américas: 690.

Guevara, Ernesto [1965] (1970). “El socialismo y el hombre en Cuba”. Obras 1957-1967. Tomo II. La Habana: Casa de las Américas: 366-384.

Guevara, Ernesto [1967] (1970). Diario de Bolivia. Obras 1957-1967. Tomo I. La Habana: Casa de las Américas: 457-630.

Guevara, Ernesto.. "Mensaje a la Tricontinental. Crear dos, tres, muchos Viet-nam”. Ruedo Ibérico 12 (1968): 84-101.

Guevara, Ernesto ( 1992). Notas de viaje. Madrid-La Habana: Abril-Sodepaz.

Guevara, Ernesto (1999). Pasajes de la guerra revolucionaria: Congo. Barcelona: Mondadori.

Guevara, Ernesto (2001). Otra vez. Diario inédito del segundo viaje por Latinoamérica. Barcelona: Ediciones B.

Guevara, Ernesto (2011). Diario de un combatiente. De la Sierra Maestra a Santa Clara (1956-1958). La Habana: Editorial de Ciencias Sociales.

Hernández, R. (2009). “El año rojo. Política, sociedad y cultura en 1968”. Revista de Estudios Sociales 33: 44-54.

Iznaga Beira, Diana. "Che Guevara y la literatura de testimonio". Universidad de la Habana 232 (1988).

Kulteischikovsk, Vera; Ospovat, Lev. "La literatura en la vida de un revolucionario. (Para un retrato de Ernesto Che Guevara)”. Casa de las Américas 104 (1977).

Lowy, Michael (1972). Elpensamiento del Che Guevara. Buenos Aires: Siglo XXI. 
Jaume Peris Blanes. Relatos para una revolución potencial...

Maccioni, Laura. "Retratos del Hombre Nuevo: figuras de la subjetividad en Pasajes de la guerra revolucionaria y 'Comienza el desfile””. Anclajes 17.2 (2013): 33-45.

Martínez Heredia, Fernando (2010). Las ideas y la batalla del Che. La Habana: Editorial Ciencias Sociales.

Massari, Roberto (1994). "El humanismo revolucionario del Che”. Guevara para hoy (ed. Massari et alli). Roma: Erre Emme Edizioni: 9-38.

Massari, Roberto (2004). Che Guevara. Pensamiento y política de la utopía. Tafalla: Txalaparta.

Mattalia, Sonia (1998). Miradas al fin de siglo: lecturas modernistas. Valencia: Tirant lo Blanch.

Peris Blanes, Jaume (2012). "Cuando digo futuro. Imaginario del desarrollo, cultura y antiintelectualismo en Cuba". La cultura en tiempos de desarrollo: violencias, contradicciones y alternativas. (Nuria Girona, eda.) Valencia: Quaderns de Filologia.

Peris Blanes, Jaume. "Reunión, de Julio Cortázar. Reescritura y conflicto de poéticas en el conflicto del intelectual y la revolución”. Hispanofila 172 (2014): 143-159. DOI: 10.1353/hsf.2014.0044

Piglia, Ricardo. 2005. "Ernesto Guevara, rastros de lectura”. El último lector. Barcelona: Anagrama. 103-138.

Pogolotti, Graziella. “Apuntes para el Che escritor”. Casa de las Américas 46 (1968).

Portuondo, José Antonio (1981). "Notas preliminares sobre el Che escritor". Capítulos de literatura cubana. La Habana.

Quintero Herencia (2002). Fulguración del espacio. Letras e imaginario institucional de la Revolución Cubana (1960-1971). Rosario, Beatriz Viterbo.

Ramos, Julio (1989). Desencuentros de la modernidad en América Latina. Modernidad y política en el siglo XIX. México: FCE.

Rotzincher, León. “Actividad intelectual y subdesarrollo”. Ruedo Ibérico 16 (1968): 15-20.

Vezzetti, Hugo (2009). Sobre la violencia revolucionaria. Memorias y olvidos. Buenos Aires: Siglo XXI.

Zygmunt, Karolina (2013). "La construcción de la experiencia del viaje en la escritura: figuras del escritor viajero contemporáneo”. Kamchatka. Revista de análisis cultural 2 (2013): 105-136.

DOI: 10.7203/KAM.2.3165 